\title{
The Perception of Flood Risks: A Case Study of Babessi in Rural Cameroon
}

\author{
Gertrud Buchenrieder $^{1,2} \cdot$ Julian Brandl $^{3} \cdot$ Azibo Roland Balgah $^{4}$
}

Accepted: 12 March 2021 / Published online: 18 May 2021

(C) The Author(s) 2021

\begin{abstract}
Although risk perception of natural hazards has been identified as an important determinant for sound policy design, there is limited empirical research on it in developing countries. This article narrows the empirical literature gap. It draws from Babessi, a rural town in the Northwest Region of Cameroon. Babessi was hit by a severe flash flood in 2012. The cross-disciplinary lens applied here deciphers the complexity arising from flood hazards, often embedded in contexts characterized by poverty, a state that is constrained in disaster relief, and market-based solutions being absent. Primary data were collected via snowball sampling. Multinomial logistic regression analysis suggests that individuals with leadership functions, for example, heads of households, perceive flood risk higher, probably due to their role as household providers. We found that risk perception is linked to location, which in turn is associated with religious affiliation. Christians perceive floods riskier than Muslims because the former traditionally reside at the foot of hills and the latter uphill; rendering Muslims less exposed and eventually less affected by floods. Finally, public disaster relief appears to have built up trust and subsequently
\end{abstract}

Gertrud Buchenrieder

buchenrieder@yahoo.de

1 Research Center RISK, Institute of Sociology and Economics, Universität der Bundeswehr München, 85577 Neubiberg, Germany

2 Leibniz Institute of Agricultural Development in Transition Economies (IAMO), 06120 Halle (Saale), Germany

3 TUM School of Life Sciences Weihenstephan, Technical University Munich (TUM), 85354 Munich, Germany

4 College of Technology, The University of Bamenda (UBa), Bamenda, North West Region, Cameroon reduced risk perception, even if some victims remained skeptical of state disaster relief. This indicates strong potential benefits of public transfers for flood risk management in developing countries.

Keywords Flood disaster - Multinomial logistic regression · Risk perception · Rural Cameroon

\section{Introduction}

Escalating natural hazards often cause enormous property damage, thereby increasing victims' vulnerability ${ }^{1}$. In the last few decades, the number and volatility of extreme natural hazards increased tremendously (CRED 2019; Statista 2020). According to the Center for Research on the Epidemiology of Disasters (CRED), the frequency of natural hazard-related disasters is on the rise, as is the damage they cause (CRED 2019). Hydrometeorological hazards alone accounted for $87 \%$ of all hazards, with floods representing about $50 \%$ of all weather related hazards between 1995 and 2014 (Birkholz et al. 2014; World Bank 2014).

Economic losses due to natural hazards and disasters are concentrated in high-income countries. ${ }^{2}$ Nevertheless,

\footnotetext{
${ }^{1}$ An earlier version of this article has been published as a book chapter by Buchenrieder et al. (2019). The chapter is part of the edited volume "Risk - Thoughts on and into the Uncertain. Interdisciplinary Negotiations of the Risk Phenomenon in the Light of Reflexive Modernity", in German language, published by Springer.

We would like to thank the anonymous reviewers for their careful reading of our manuscript, their insightful comments and constructive suggestions, which helped us to improve this article. All remaining errors are our own.

2 Countries with a gross national income per capita of less than or equal to USD 12,235 (of 2016 value) are defined as developing countries, above as high-income countries (OECD 2018).
} 
there is a general consensus that natural hazards are more severe in developing countries, especially in terms of their negative and largely irreversible impacts on livelihoods, natural and physical resources, and ecosystems (Ahsan 2011; Fondo et al. 2018). Around 85\% of the globally affected population lives in developing countries and $47 \%$ reside in rural areas (UN DESA 2015). In fact, over $90 \%$ of the population in developing countries lives in rural areas (UN DESA 2015). According to Lumbroso et al. (2016), floods and droughts are the two natural hazards that have had the largest humanitarian impacts in Africa over the past 30 years based on the number of people affected. However, in the past decade, across Africa, floods have overtaken droughts in terms of the number of people that they impacted negatively (Lumbroso 2020). Kendon et al. (2019) forecast many extreme outbreaks of intense rainfall over the next 80 years across Africa, triggering devastating floods with loss of property and life, displacement, and disruptions of farming. They emphasize that intense rainfalls that were forecasted to occur in a region every 30 years are more likely to happen every three to four years, mainly due to climate change.

Flood risk perception affects risk management and, therefore, determines whether risk management is successful in reducing community vulnerability or not (Bubeck et al. 2012). Although risk perception of natural hazards has been an important topic for a few decades now, there is still limited empirical research on flood risk perception in sub-Saharan African countries and even less in rural regions (Fondo et al. 2018). We contribute to closing this research gap by examining risk perception among victims of a flash flood in the rural town of Babessi in the Northwest Region of Cameroon, which occurred on 9 September 2012. ${ }^{3}$ The article attempts to answer the question: What determines the flood risk perception of the residents of a rural town in Cameroon who have been disastrously hit several times by a flash flood? Justification for place-based risk research arises from the fact that (1) no two natural (flood) hazards are exactly the same; (2) flood effects are influenced by regional and social context; and (3) flood hazard management strategies should be context adapted (Hisali et al. 2011; Fondo et al. 2018; Lechowska 2018). We approach the research with a cross-disciplinary theoretical grounding. This approach recognizes the complexity inherent to risk perception analyses.

Risk perception is considered as an individual and intuitive assessment of the perceived risk of a hazard and its often disastrous consequences in the context of limited or uncertain information (Slovic 2000). Risk perception

\footnotetext{
${ }^{3}$ We thus contribute to one of the priorities spelled out by the Sendai Framework for Disaster Risk Reduction 2015-2030: understanding disaster risk (UNISDR 2015, p. 14).
}

influences eventual response to the hazards (Peters and Slovic 1996). Risk perception analysis thus reveals what people perceive (awareness), why they perceive it that way $\left(\operatorname{dread}^{4}\right)$, and how (if at all) they will subsequently manage the negative effects linked to the hazard (preparedness) (Lave and Lave 1991; Wachinger et al. 2013). Lechowska (2018) summarizes awareness, dread, and preparedness as the "triangle" of risk perception. From a policy point of view, risk perception and its influencing factors determine the attitude (the level of preparedness for a flood) and the possible behavior of potential victims when actually faced with a flood (Gebrehiwot and van der Veen 2015). According to Rogers and Prentice-Dunn (1997), risk perception and the associated threat of pain and suffering motivate people to take protective action. In addition, knowledge of the factors affecting risk perception is primordial for more effective flood information and management strategies (Birkholz et al. 2014; Lechowska 2018).

The next section reviews the literature on risk perception related to natural hazards and summarizes the cross-disciplinary theoretical grounding for risk perception research. Importance is attached to clearly differentiate between relevant terms in risk perception research, namely natural hazard, disaster in a social context, risk, and risk perception. The comprehensive theoretical grounding is pertinent for identifying and soundly interpreting factors affecting risk perception. Section 3 highlights the study area and discusses the materials and methods. The place-based risk research is linked to the rural town of Babessi in Cameroon. This town has an increased risk of flash flooding ${ }^{5}$ because it is situated in the Ngoketunjia Division on the Ndop Plain, a valley surrounded by a mountain chain consisting of Bamenda Mountain and the Oku Massif. Section 4 , organized along the major paradigms theorizing risk perception, presents and discusses the empirical results. The final section concludes and summarizes limitations of the research.

\footnotetext{
${ }^{4}$ In the context of risk perception research, some scholars (for example, Lechowaska 2018), use the terms worry or fear instead of dread. Kierkegaard (1991) distinguishes between fear and dread. Fear is directed towards an external danger (object-related affect) and dread is rather undirected or indeterminate. Obviously, the human affect associated with the risk perception of a natural hazard can be both, object-related and somewhat indeterminate.

5 A flash flood is defined as a "rapid inland flood due to intense rainfall [...] with short duration" (CRED 2019, https://www.emdat. be/explanatory-notes \& https://emdat.be/glossary, accessed 5 Feb 2019).
} 


\section{Natural Hazards, Disaster, Risk, and Theoretical Grounding of Risk Perception}

Natural hazards are natural, but hazards do not have a disastrous impact without a social context. Risk is a probabilistic measure of hazards, whereby meanwhile socioeconomic factors are included in the objective risk measure. Therefore, the nature of hazards is classified as well as their social impact in the form of disasters. Risk perception in the context of the occurrence of a hazard captures the subjective evaluation of the hazard and the resulting possible disaster. After having clarified this hazard-disaster-risk perception continuum, the most prominent theoretical paradigms underlying risk perception are summarized.

\subsection{From Natural Hazard to Disaster}

In general, hazards are "threats to humans and what they value" (Kates and Kasperson 1983, p. 7029; Slovic et al. 1985, p. 91). In other words, hazards are the threatening events (Bradford et al. 2012). Based on their nature, hazards can be further divided into (1) natural hazards, (2) technological hazards, and (3) violence and war hazards. This contribution focuses on natural hazards. There are numerous, more general definitions of natural hazards. In spite of disparities, they are generally conceived as uncommon and extreme events of geophysical, atmospheric, hydrological, or biological nature with the potential to cause harm (for example, loss of life) or loss (for example, loss of property, economic disruption, and environmental damage) (Benson and Clay 2004; Alexander 2009; UNISDR 2009; Bokwa 2013).

Natural hazards can be further classified on the basis of their origin: (1) within earth such as earthquakes, (2) on earth's surface such as landslides and floods, and (3) above the earth such as storms (Stillwell 1992). Another classification follows the time of occurrence, the speed of onset, and the duration of the natural hazard (Bokwa 2013). Some hazards can occur at any time of the year (for example, tsunamis or thunderstorms) whereas others occur at a certain time of the year (for example, hurricanes). Hurricanes for instance can be detected hours or days in advance. However, earthquakes cannot be precisely forecasted. With regard to the duration and impact, an earthquake may last for seconds (but the aftershocks go on for weeks), and a flood a few minutes or for weeks; both with effects that can be of long duration (Middelmann 2007). Droughts differ from other natural hazards due to their slow-onset and the difficult determination of their end (Wilhite 2000). Naturally, a drought simply means lack of rainfall (Neisi et al. 2020).
A natural hazard can lead to a disaster (Bokwa 2013). However, there exists no generally agreed definition of what constitutes a disaster (Alexander 2000; Smith 2013). According to Sivakumar (2005), a natural hazard-related disaster exists when a hazard leads to socioeconomic and/ or environmental calamitous consequences. The Munich Reinsurance Company speaks of a disaster "if any property is damaged and/or any person [is] sincerely affected (injured, dead)" (Below et al. 2009, p. 3). The EM-DAT under CRED defines a disaster as involving 10 or more people being killed and/or 100 or more people being affected and/or if the affected country/region declares a state of emergency or is calling for international assistance (CRED 2019). Similarly, UNISDR (2009, p. 9) outlines a disaster as a "serious disruption of the functioning of a community or a society involving widespread human, material, economic or environmental losses and impacts, which exceeds the ability of the affected community or society to cope using its own resources." Therefore, and irrespective of consistency in definitions, a disaster seems to only exist if the hazard results in some serious losses, however defined.

\subsection{Hazard versus Risk}

What is risk? Are risks synonymous to hazards? Kates and Kasperson (1983, p. 7029) distinguish hazard and risk as follows: "A hazard [...] is a threat to people and what they value (e.g., property, environment, future generations, etc.) and a risk is a measure of hazards." Risk can thus be defined as the "probability of some adverse effect of a hazard" (Short 1984, p. 711). Kron $(2002,2005)$ defines a flood risk as follows: Flood risk $=$ hazard $\times$ values $\times$ vulnerability.

This more sophisticated definition portrays risk as the intersection between a hazard, the exposure of people/assets to the hazard, and the vulnerability of the people/assets that are exposed (Birkholz et al. 2014). This definitional approach is inherent to socioeconomic research in the field of natural hazards. Sociological and behavioral research considers risk as an inherent attribute of human decision making (Bonß 1996; Birkmann 2013). Actions or events (such as hazards) prompt decisions whose variability leads to different consequences (Luhmann 1993). Consequently, the decision-making process connotes taking a risk, for instance when deciding to get or not to get prepared for a natural hazard, possibly occurring in the future (Bonß 1996; Rogers and Prentice-Dunn 1997; Birkmann 2013; Birkholz et al. 2014). In such a social system, the willingness and capability to take a risk is also influenced by the interaction between the potential disaster resulting from a hazard (Bokwa 2013) and the individual, physical, and social vulnerability of possible victims (Kron 2002, 2005). 
Thus, disaster victims not only face different probabilities of experiencing adverse effects of a hazard but also display different degrees of vulnerability. The concept of vulnerability has become particularly important within natural hazard and disaster research because it encapsulates how social contexts shape risk (Birkholz et al. 2014). The social context of vulnerability interacts with the geographic context to create "place vulnerability" (Rogers and Prentice-Dunn 1997; Birkholz et al. 2014). This may lead to varying decisions and thus to varying risk perceptions (and vice versa). Definitions of "risk perception" must inevitably draw from characterizations of risk itself (Birkholz et al. 2014). Risk perception has achieved widespread recognition in the general risk management literature because "perceptions of risk and risk related behaviors may amplify the social, political, and economic impact of disasters well beyond their direct consequences" (Burns and Slovic 2012, p. 579). Furthermore, most people include experiences, emotions, and feelings in their perception of risk, producing a measure that relies on intuitive risk judgements (Bradford et al. 2012).

\subsection{Cross-Disciplinary Theoretical Grounding of Risk Perception Research}

Discourses on risk perception are fundamentally rooted in the social sciences and psychology. Traditionally, risk perception research investigates how individuals evaluate (and react to) risks associated to a hazard (Luhmann 1993), whereby a hazard can lead to a disaster when facilitated by social context characteristics. Risk perception therefore captures the subjective evaluation of the probability of the occurrence of a certain calamity and the individual's anxiousness with the consequences (Slovic 1987, 2000; Sjöberg et al. 2004; Bradford et al. 2012; Lechowska 2018). This subjective assessment of risk depends on the type and magnitude of risk faced, the individual's vulnerability, the social context, and psychological or cognitive attributes such as former experience with the hazard in question (Oltedal et al. 2004; Wachinger et al. 2013), the individual's perceived capacity to take action, and the protective response efficacy (Rogers and Prentice-Dunn 1997; Groothmann and Reusswig 2006; Mertens et al. 2018). Underlying risk perception is the process of collecting, selecting, and interpreting signals about uncertain negative impacts of hazards (Wachinger and Renn 2010).

The theoretical paradigms of risk (perception) research can be broadly delimited along psychological, normative, cultural, cognitive, and social constructions. In the following, prominent theoretical paradigms of risk perception research are summarized. We follow here the call of Birkholz et al. (2014) to re-examine and re-invigorate flood risk perception research by more constructivist thinking.
This review structures the cross-disciplinary lens to risk perception research adopted here, in order to uncover parameters that often lie latent in disciplinary narratives. They include: (1) mental models; (2) psychometric paradigm; (3) orienting dispositions such as affects and worldviews; (4) socioeconomic and demographic models; (5) cultural theory; (6) trust-oriented concepts; (7) location and experience-oriented concepts; and (8) the protection motivation theory.

\subsubsection{Mental Models and Risk Perception}

Mental risk perception models capture how people think about their particular hazard situation, what they know, and what they (mis)perceive about the facts and processes related to causation, damage, and mitigation of eventual hazards (Peters and Slovic 1996). The mental model approach reveals surprising insights. An interesting finding is that people appear to deny the possible reoccurrence of a hazard they experienced, saying it could not or would not happen again. Also, when asked about what they know about floods, they focused on the largest flood they had experienced rather than on the most recent flood (Lave and Lave 1991). Under such circumstances, those affected are often reluctant to take precautionary measures. Instead of concluding that people do not heed advice on mitigating hazardous effects, the true reason may be ignorance, fatalism, or a perceived lack of self-efficacy and measureefficacy (Rogers and Prentice-Dunn 1997; Mertens et al. 2018). The mental model approach is often supplemented by demographic information. Education for instance may influence how a hazard is perceived because it affects the individual's cognitive maps. Furthermore, education influences how and which information is sought and how knowledge is generated. Direct hazard experience may also influence these cognitive maps (Lechowaska 2018). Mental models are quite robust and have found solace in the psychometric paradigm as well as in the concept on affect and worldviews (Peters and Slovic 1996), further explained in Sect. 2.3.2 and 2.3.3.

\subsubsection{Psychometric Paradigm and Risk Perception}

The psychometric paradigm, mainly driven by Fischhoff et al. (1978) and Slovic (1987), depicts that risk is subjectively perceived, whereby each individual is influenced by a wide array of psychological, social, institutional, and cultural factors (Sjöberg et al. 2004). Risk perception research that is based on the psychometric paradigm identified two factors, namely dread and novelty of the risk, explaining a substantial part of the variation in risk perception. A dread risk is defined by the extent of perceived lack of control, feeling of dread, perceived catastrophic 
potential, and the inequitable distribution of risks. An unknown, novel risk can be defined by the degree to which a hazard is judged to be unobservable, unknown, new, and delayed in producing harm (Fischhoff et al. 1978).

\subsubsection{Affect and Worldviews as Orienting Dispositions in Risk Perception}

Peters and Slovic (1996) expand on the psychometric paradigm by hypothesizing that risk perception also corresponds to worldviews and affect-laden imagery in terms of orienting dispositions. Worldviews are defined as generalized attitudes toward the world and its social organization. Affect is an emotional impulse (for example, dread) that is triggered by external events and/or internal psychometric attributes. How a person feels about a hazard, that is, his/her affective reaction, influences risk perception (Raaijmakers et al. 2008).

Religion, education (knowledge), and information influence worldviews and/or affect. Rogers and PrenticeDunn (1997) highlight information as a factor that initiates cognitive mediating processes with regard to the possible responses to the perceived risk. Messner and Meyer (2005) claim those having little knowledge about causes of natural hazards have a lower risk perception. The resulting orientating disposition guides people in hazard situations and influences their risk perception (Dake 1991, 1992). However, questions of ancestral belief (faith) and religious perceptions are rarely addressed in the context of risk perception, although some 6 billion people belong to a religion. Yet, taking precautionary action is determined by a wide variety of beliefs and practices (Schipper 2010). Education in combination with information about risk usually changes affect and worldviews and thus influences risk perception (Raaijmakers et al. 2008).

\subsubsection{Socioeconomics, Demography, and Gender in Risk Perception}

Socioeconomic aspects, such as owning rather than renting a house or an apartment is usually connected with a higher level of risk perception (Qasim et al. 2015) even if this relationship cannot be generalized (Kellens et al. 2011). The role of demographic factors (for example, age, education) and gender in risk perception is also debated. Empirical evidence suggests that demographic factors influence risk perception (Peakcock et al. 2005; Bang 2008; Botzen et al. 2009; Kellens et al. 2011; Yu et al. 2017) but there is also evidence against it (Plapp and Werner 2006; Bronfman et al. 2016). The uniqueness of many hazards and the case-specificity emanating from place-based studies appear to generate contradicting empirical outcomes, emphasizing the need for more empirical studies.
Income diversification has been identified as a major risk reducing, ex ante strategy employed by the rural poor, such as farmers and women in large parts of sub-Saharan Africa (Seo 2010). However, as many of the income sources of a diversified portfolio remain tied to the major source of income and the well-being of the community, any shock that hurts the major income source and the community can place the diversified income in jeopardy. Molua (2011) states that a disaster that creates farm yield losses and farmland damages can have devastating impacts on all sources of income in Cameroon. Peacock et al. (2005) found in their U.S. hurricane perception study that people with low income and low educational attainment, women, and ethnic minorities tended to perceive risk higher than the opposite socioeconomic groups. There may be interaction effects between low education and low income, between low education and specific ethnic groups, or between low income and women. The emerging vulnerable socioeconomic situation may make them more susceptible to perceiving potential hazards as more perilous (Mertens et al. 2018).

\subsubsection{Culture, Social Construct, and Risk Perception}

Culture and social construct explain how people perceive and understand risk. Culture, for instance, provides socially constructed myths about nature (Dake 1992). As mentioned by Wildavsky and Dake (1990, p. 42), the cultural theory of risk can "predict and explain what kind of people will perceive which potential hazards to be how dangerous." According to the cultural theory, risk perception is related to the way of life, which is linked to the "cultural bias" and "social construct" of an individual (Oltedal et al. 2004). Cultural biases are defined as shared values and beliefs, that is, as worldviews corresponding to different patterns of social relations. Cultural theory expects a "strain to consistency" in individuals but recognizes that different cultural biases may dominate different parts of people's lives (Johnson and Swedlow 2021). Grid and group are two important dimensions for identifying social relations. Johnson and Swedlow (2021) summarize that grid allows to understand the extent to which relations are prescribed (for example, by rank, role, and gender); and group the extent to which relation patterns are bounded (for example, us versus them). Social relations are defined as one of five patterns of interpersonal relationships, namely hierarchical, individualist, egalitarian, fatalist, and hermit, a zero grid and group type (Dake 1991). However, the empirical support for this theory has been surprisingly meager, and even less from developing countries (Oltedal et al. 2004; Johnson and Swedlow 2021). Social categories, for instance, hierarchy in the form of prescribed leadership positions (for example, elders, household heads) may 
perceive risk differently than other social categories. In addition, the ambiguity regarding gender may be a consequence of the phenomenon of "cross-cultural, cross-gender reversal," implying "an influence of gender on risk perception [stemming] from cultural and social factors" (Lechowska 2018, p. 1353).

\subsubsection{Trust and Risk Perception}

Trust is a necessary prerequisite for dealing with hazards, especially considering the limits of risk perception as a function of awareness and preparedness (Lechowska 2018). Oswald (1994) distinguishes five types of trust, among them trust in friends (Freundschaftsvertrauen) and trust in strangers (Fremdvertrauen). Trust in friends assumes goodwill; this is not a necessary aspect when it comes to trust in persons external to one's own social construct. In developing countries, trust based on friendship is often observed among members of self-help and mutual aid groups. State and local government authorities and other potential sources of support and information are perceived as outsiders. Nevertheless, it is plausible to assume that trust based on friendship as well as trust in outsiders such as public authorities is influencing risk perception, especially if own knowledge and information about the hazard is low (Wachinger et al. 2013). The more knowledgeable an individual is regarding the hazard risk, the more he/she will make own decisions and rely less on others such as friends and/or strangers (Siegrist and Cvetkovich 2000).

In the context of infrequently occurring hazards, however, people may depend more on information by persons outside the own social construct. If trust in external sources of support and information is weak, on the one hand, individuals feel more at risk (Bronfman et al. 2016). A high degree of trust, on the other hand, can lower risk perception and reduce the intention to take own precautionary measures in light of possible future hazardous events (Paton 2008). Trust in authorities may thus potentially create a false sense of safety (Lechowska 2018).

\subsubsection{Location, Experience, and Risk Perception}

Individuals may have had different hazard experiences that may be linked to their place of living (Messner and Meyer 2005; Bradford et al. 2012; Yu et al. 2017). Peacock et al. (2005) argue that location is an under-examined factor in explaining risk perception. Wachinger et al. (2013) distinguish between "direct" and "indirect" hazard experiences. A direct experience is, for example, seeing and experiencing the hazardous event with one's own eyes. Indirect experience is external, for example, hearing of an event through the media or other people. However, having been living (for a longer period) in a (natural) disaster zone and having direct experience is claimed to be one of the most important factors of risk perception (Bustillos Ardaya et al. 2007; Botzen et al. 2009; Kellens et al. 2011; Wachinger et al. 2013). Individuals with direct hazard experience may find it easier imagining a similar, future hazard and, therefore, may perceive a higher risk than individuals without similar experience (Botzen et al. 2009). People who were directly affected by a hazard may therefore decide to better prepare for future hazards (Siegrist and Gutscher 2008). Previous hazard experience can, however, also lead to a lower perceived risk associated with such an event in the future, with former victims assuming that they are less amenable and less vulnerable to future events and their negative impacts (Halpern-Felsher et al. 2001; Peacock et al. 2005).

Obviously, experience is linked to location, length of residence, and age. People who have resided in a disaster zone longer and/or older persons often have more hazard experiences than those with shorter residence or younger persons. The results regarding length of residence imply a positive but weak correlation with risk perception (Bustillos Ardaya et al. 2007). Kellens et al. (2011) report that elderly people have a higher risk perception. Botzen et al. (2009), Peacock et al. (2005), and Yu et al. (2017) find the opposite.

Furthermore, the type of hazard experience is important in risk perception. Even if all individuals in an area affected by a natural hazard, for example, a flood, claim to have directly experienced the flood hazard, not all of them might have experienced harm or loss (Botzen et al. 2009; Wachinger et al. 2013). This could further influence preparedness (Rogers and Prentice-Dunn 1997). However, if the experienced hazard is infrequent and not severe, people may have a false sense of security. This may lead to misjudgment of the ability to manage the risk (Raaijmakers et al. 2008; Wachinger et al. 2013).

\subsubsection{Protection Motivation Theory and Risk Perception}

The protection motivation theory (PMT) is based on the seminal work of Rogers $(1975,1983)$ and is delimited along cognitive and physiological constructions. It is grounded in health psychology but is meanwhile increasingly being used to explain protective behavior in the presence of natural hazards (Mertens et al. 2018; Wuepper et al. 2020). It has many points of contact with the first three theoretical paradigms discussed above: the mental models, the psychometric paradigm, and the orienting dispositions such as affects and worldviews. For instance, the theoretical paradigm of orienting dispositions such as affects and worldviews and the PMT refer both to (persuasive) information and messages, which can stimulate cognitive mediating processes and subsequent changes in 
risk coping and management behavior. The PMT, however, also mentions the importance of the individual's personality or dispositional characteristics, that is, non-cognitive skills (Wuepper et al. 2020), which are discussed above under the heading "socioeconomics, demography, and gender in risk perception." Interestingly, the PMT considers prior experience with hazard related disasters as a largely underappreciated factor initiating cognitive mediating processes (Rogers and Prentice-Dunn 1997). In the theoretical paradigm associated to "location, experience, and risk perception," experience was found to go both ways. It can motivate former victims of disasters to better prepare for future hazards, but it can also give them a false feeling of security. Bonß (1997) gives reason to this phenomenon based on the selective perception of actual insecurity: The only way to feel safe is to assume that nothing is going to happen. However, the PMT emphasizes the change in attitude and behavior due to the motivational role of risk perception (termed threat appraisal in PMT) and the associated threat of suffering (Rogers and Prentice-Dunn 1997; Floyd et al. 2000). The central message of Rogers and Prentice-Dunn (1997, p. 113) is that risk perception motivates people to take protective actions in order "to avoid the unpleasant consequences of not taking those actions." The central factors highlighted in the PMT are the severity of the potential disaster, the vulnerability of the threatened, the individually perceived self-efficacy to respond to the thread, and the belief that the recommended action to manage the threat is effective (Rogers and Prentice-Dunn 1997). Two distinct but related processes occur in response to the risk and to prevent the negative impacts: the cognitive process and the protective responses (Delfiyan et al. 2021). Thus, the PMT is closely linked to the perceived adaptive capacity of those at risk in anticipation of the next natural hazard and disaster (Wuepper et al. 2020). Adaptive capacity refers to an individual's or group's general ability to make adjustments so as to become more effective at dealing with the disastrous consequences of hazards (Birkholz et al. 2014).

\section{Study Area, Data, and Parametric Model}

The empirical data relate to Cameroon. Its geographical location, geological composition, tectonic history, and climatic zones make it one of the most exposed and affected countries by natural hazards in sub-Saharan Africa.

\subsection{Study Area}

The place-based study relates to the subdivision of Babessi and the rural town Babessi (around 25,000 inhabitants in
2015) in the Ngoketunjia Division in the Northwest Region of Cameroon (Fig. 1a). Babessi Subdivision is situated in the Ndop Plain, a valley surrounded by a mountain chain consisting of Bamenda Mountain and the Oku Mountain, which is part of the Cameroon volcanic line (Fig. 1b). The Ndop Plain is located between the latitudes $6^{\circ} 50^{\prime} \mathrm{N}$ and $6^{\circ} 39^{\prime} \mathrm{N}$ and longitudes $10^{\circ} 23^{\prime} \mathrm{E}$ and $10^{\circ} 28^{\prime} \mathrm{E}$, covering a surface area of about $240 \mathrm{~km}^{2}$ with a mean annual rainfall of $1,700 \mathrm{~mm}$. The climate is equatorial with two seasons: a rainy season of eight months (mid-March to mid-November) and a dry season of four months. Torrential down pours ushered in by the monsoon winds characterize the rainy season, at times accompanied by destructive storms. The Ndop Plain is drained by the Nun River (Fig. 1a) and its numerous tributaries. The Bamendjin Dam, constructed on the upper Nun River further down the Ndop Plain (Fig. 1b), increases the risk of floods because the dam has caused the water table to rise in many areas of the Ndop Plain. This makes the subdivision prone to flash flooding. The situation is aggravated by the failure of the state to maintain and manage effective drainage systems (Aka Tangan et al. 2018).

On 9 September 2012, Babessi was hit by a severe and fulminating flash flood. The flood lasted only for $30 \mathrm{~min}-$ utes (18:30-19:00). Among other assets, 56 houses were destroyed. Furthermore, the flood washed away some 160 ha of crops (notably swamp rice, cocoyam, plantains, and beans) belonging to around 140 farmers. Human losses were serendipitously low, nevertheless, the flood constituted a disaster according to the definition of UNISDR (2009). Due to the good road access, humanitarian help quickly reached the town and was provided by state and nonprofit organizations (Balgah et al. 2015).

The Senior Divisional Office (SDO) of the Ngoketunjia Division, the territorial administrative agency of the Cameroonian government, treated only those families whose houses had collapsed as flood victims. Those whose houses had been damaged received little or no disaster relief from the SDO. Figure 2 displays pictures of some destroyed houses in 2012 and ongoing reconstruction in 2015. Disaster relief included stones for a sturdy foundation of the mud-brick houses (see Fig. 2b). Furthermore, the beneficiaries of state disaster relief cash out reported that they had to repay FCFA 10,000 (about USD 17, about the wage of a day laborer for seven days) to the representatives of the SDO. They did not know why they had to repay part of the relief sum, but it is plausible to assume that the representatives of the SDO enriched themselves (Pohlmann 2015). 


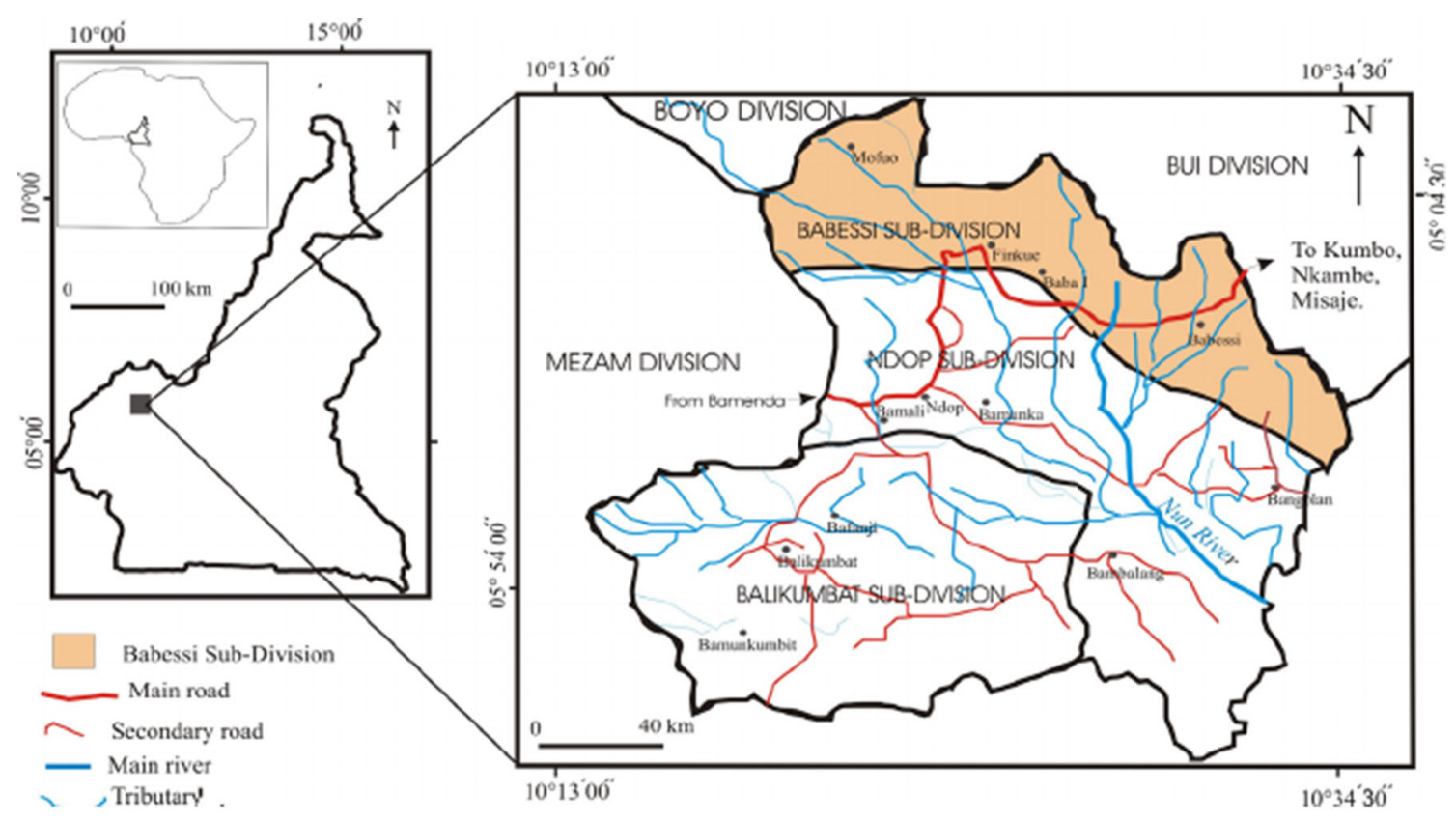

(a)

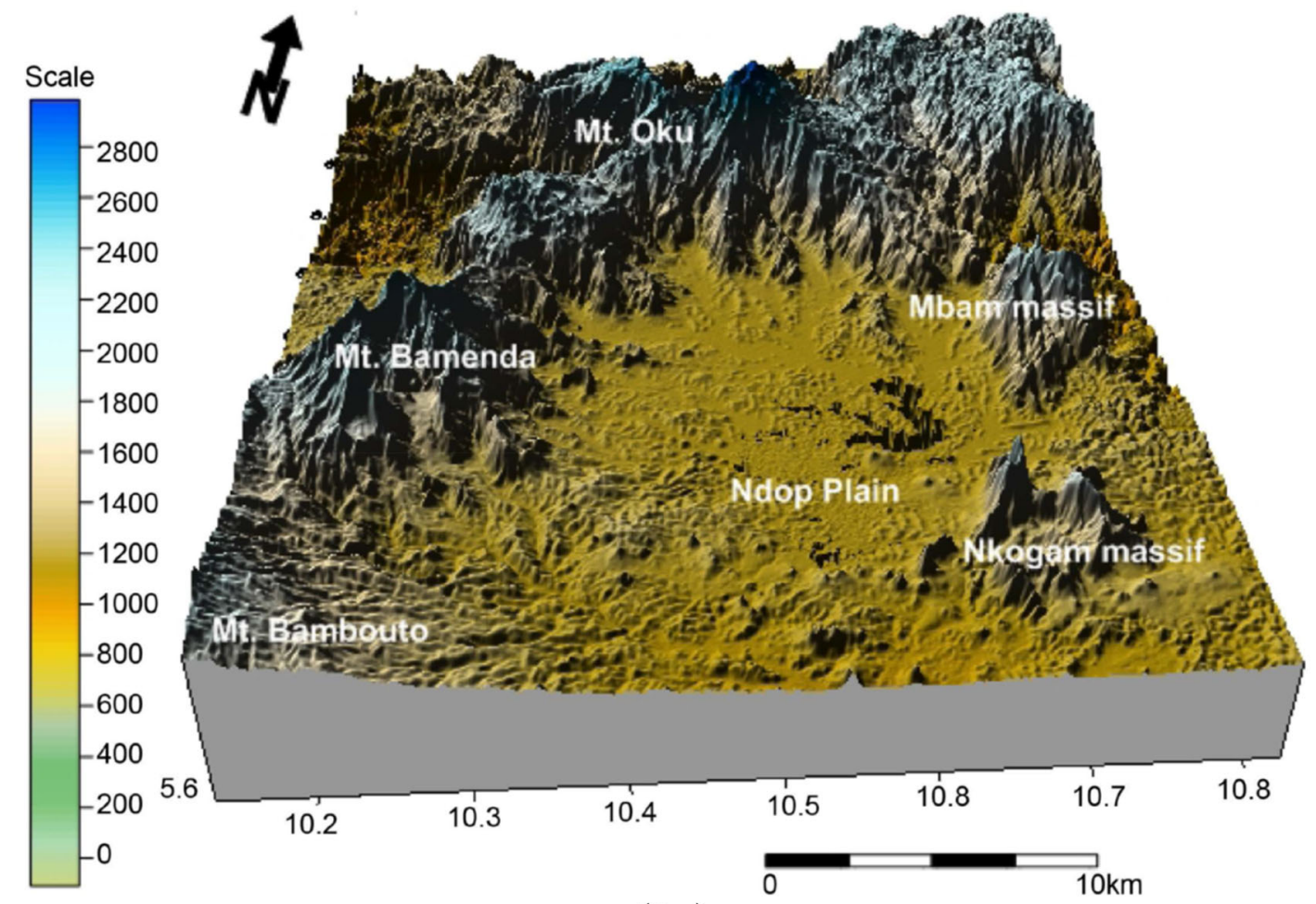

(b)

Fig. 1 Geographical location of Cameroon and the study area. a Location of Babessi Subdivision in Ngoketundjia Division, Cameroon and Africa; b Digital elevation model of the Ndop Plain.
Sources a Aka Tangan et al. (2018, p. 214); b Modified by Aka Tangan et al. (2018, p. 215), adapted from Wotchoko et al. (2016, p. 430) 


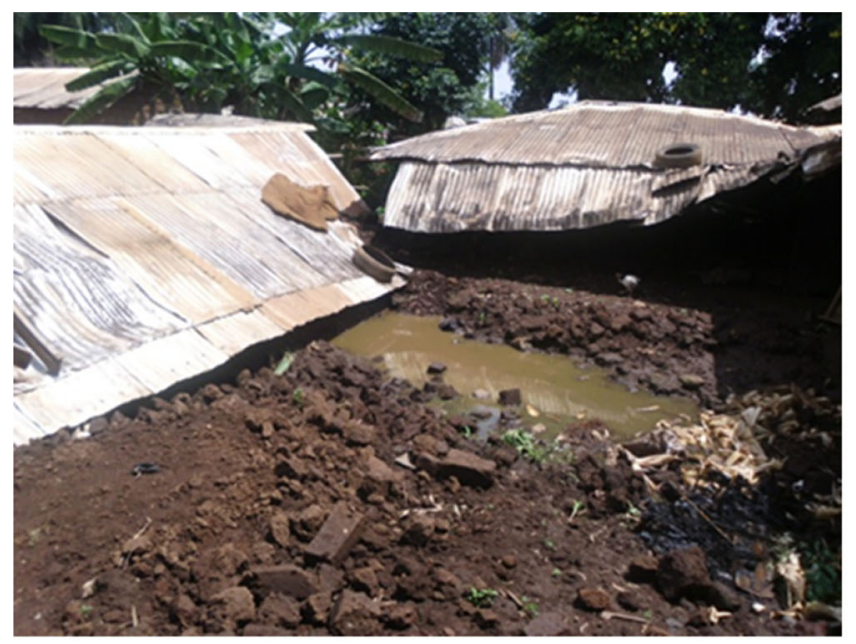

(a)

Fig. 2 Three years after the 2012 flood in Babessi-reconstruction of destroyed mud-brick houses still ongoing. a Destroyed mud-brick houses after the flood in 2012; b Reconstruction of houses with stone-

\subsection{Data Collection and Sample}

The impact of the flood related disaster on the Babessi residents' livelihoods was first surveyed 6 weeks after the disaster in 2012 to assess the preliminary impacts of the floods on the livelihoods of victims. At the time, only $5 \%$ of all victims had fully recovered (Balgah et al. 2015). In summer 2015, Pohlmann (2015)—as part of her Master's thesis work-undertook a second survey in Babessi to study gender related differences with regard to vulnerability from natural hazards. The emphasis was on the Babessi flash flood of 2012. Her empirical work was supervised by two of the authors of this article, Balgah and Buchenrieder, and her survey data are the basis of this analysis. Shortly after the 2015 survey, on 14 September 2015, the area was hit again by a flood. On 5 August 2019, Ngoketundjia Division was hit by another flood. ${ }^{6}$ Due to time and cost limitations, the 2015 sample was restricted to $138(54.5 \%)$ flood victims and $115(45.5 \%)$ non-victims. The composition of the sample was based on snowball sampling. Almost $70 \%$ of all respondents were worried of floods. As pointed out earlier in the discussion of the theoretical paradigms, especially the psychometric and the paradigm related to location and experience, living in a natural disaster zone, having direct experience, and dreading the hazard are important factors of risk perception (Bustillos Ardaya et al. 2007; Botzen et al. 2009; Kellens et al. 2011; Wachinger et al. 2013). Clearly, floods are not novel risks (Fischhoff et al. 1978) to the residents of Babessi.

\footnotetext{
${ }^{6}$ Read more on the floods here: https://www.greenvision.news/afterbabessi-bambalang-bangolan-baba-i-risk-flooding/.
}

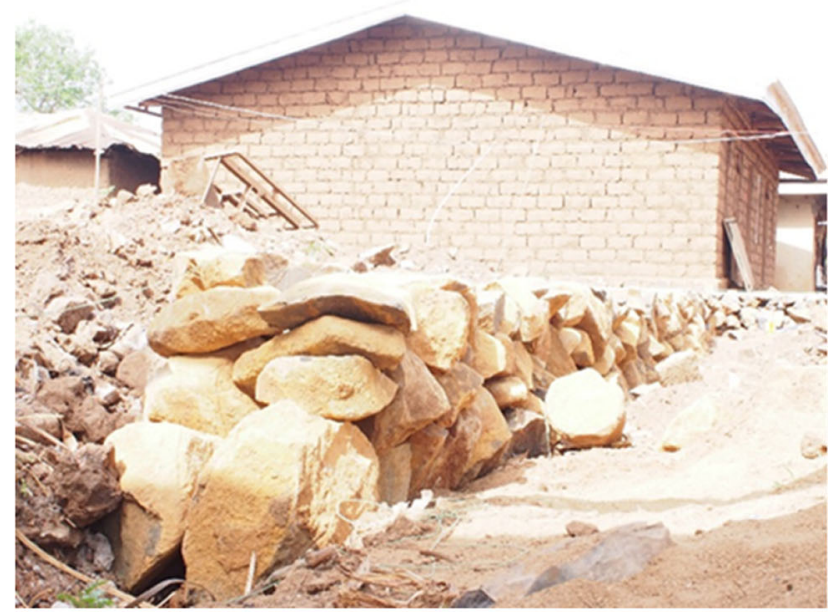

(b)

reinforced foundation ongoing, in 2015. Source a Balgah (2012); b Pohlmann (2015)

A structured questionnaire was developed following Balgah et al. (2015). The first section of the questionnaire was devoted to collect demographic and socioeconomic data, the second section to the disaster experience and risk perception. Subsequent sections addressed occupation and income creating activities, time allocation, decision making, access to productive capital, and leadership roles. In total, the questionnaire contained 90 questions. The questionnaire was pretested and administered in a paper-andpencil survey by trained local enumerators.

The types of natural hazards and disasters included in the risk perception assessment of 2015 were based on earlier qualitative research in Babessi. Balgah et al. (2015) had asked the inhabitants of Babessi "in addition to floods, which other natural hazards have been affecting Babessi town?" The qualitative interviews revealed storms with violent winds and landslides. In addition to these and based on their importance in terms of their frequency in developing countries (including Cameroon), droughts and earthquakes were added to the structured questionnaire. Furthermore, information was gained regarding the responses of humanitarian agencies, including the state (Pohlmann 2015). Whether or not the respondents had received public disaster relief in the aftermath of the 2012 flood was determined by referencing a beneficiary list obtained from the SDO.

\subsection{Description of Variables}

The target variable "risk perception" was assessed using a Likert-scale: "On a scale from $1-5$, with 1 representing 'not dangerous' and 5 'highly dangerous,' how will you 
rate the danger of being harmed by one of the following natural hazards: storm, drought, earthquake, landslide, and flood in Babessi?" Note that the words risk and danger are semantically related words (Boholm 2011). Nevertheless, while risk refers to a potential future loss as a consequence of a decision, danger is not conceived to be the result of a decision, but rather as a potential loss resulting from something external to the one affected (Luhmann 1993). However, Boholm (2011) empirically found that the frame element of "decision" is commonly realized in the term risk and danger. Furthermore, we are confident that the term danger captures the individual's anxiousness with the consequences (Sjöberg et al. 2004). Therefore and because the general schooling level is low in most rural areas of developing countries (for example, only $25 \%$ of the respondents in this study had post-primary school experience), we used the ordinary language term danger to assess risk perception after having pre-tested the questionnaire. Table 1 summarizes the respondents' risk perception of being harmed by one of these natural hazards. It is evident that the average perceived risk is highest for flood hazards (mean of Likert score is 3.86); 65\% of the respondents perceive it as (highly) dangerous. Storm hazards are perceived as constituting an elevated danger too (3.57). This can be explained by the aforementioned heavy rainfalls in the neighboring hills of Babessi, which were identified as the main hydrometeorological reason for the flash flood. As one of the respondents said: "Sometimes, we have heavy runoffs here in Babessi town. These runoffs are frequent when rain falls in the hills that surround the village. This means that we are exposed to heavy runoffs, even if it does not rain in Babessi" (Martha, a female flood victim in Babessi).

Because flood hazards constitute more than $50 \%$ of all natural hazards in developing countries (World Bank 2014; Statista 2020) and because the respondents perceived flooding as most dangerous, the focus of the analysis here is directed towards flood risk perception. The risk perception parameters depicted in Table 2 represent a cross-disciplinary intersecting set that is based on the review of the dominant theoretical paradigms underlying risk perception research.

Table 3 summarizes frequency statistics of the predictors. The age of the respondents ranged from 15 to 100 years, averaging 41 years. The household size was 7.8, above the national average of 5.2 persons. More than half of the respondents $(51 \%)$ were illiterate. The culture of self-help and mutual aid is widespread in sub-Sahara Africa, also in Cameroon. The absence of public social services, for the most part, motivates this privately organized provision of social assistance. This is reflected in the fact that about $72 \%$ of the respondents were active in a selfhelp or mutual aid group.

\subsection{Study Limitations}

This study has some limitations. First, data collection was carried out about three years after the flash flood in Babessi. This might cast doubt regarding respondents' answers concerning their risk perception at the time of the disaster. Yet, Lindell et al. (2015) state that people remember events well that were personally relevant to them. This statement was confirmed during the pre-testing of the questionnaire in Babessi (Pohlmann 2015), during which the test-interviewees responded clearly. Therefore, we are confident in the analytical results of the collected data.

Furthermore, the primary data used here were originally collected to analyze gender sensitive vulnerability issues in the aftermath of the 2012 Babessi flood. Therefore, the data did not allow constructing psychometric, affective, or adaptive capacity predictors. ${ }^{7}$ Nevertheless, there is a very good overlap with the predictive variables identified by Lechowaska (2018), who undertook an informative review of 50 empirical studies on flood risk perception in the last 20 years (see footnote 6). Furthermore, implications for the adaptive capacity to reduce the risk from floods are deduced from the risk perception discussion.

\subsection{Data Analysis and Choice of Parametric Model}

Although the questionnaire used by Pohlmann (2015) originally surveyed five categories of risk perception, the dependent variable was ultimately reduced to three categories (see Table 1) to coincide with the econometric specification, to have at least 25 observations per category of the dependent variable (Backhaus et al. 2016). The first two categories of the dependent variable ("not dangerous" and "slightly dangerous") as well as the third and the fourth category ("more or less dangerous" and "somewhat dangerous") were merged to "not or slightly dangerous" and "dangerous" respectively. Only $7.5 \%$ of the 253 respondents considered floods as "not dangerous." Between 15 and $17 \%$ perceived flooding as "more or less dangerous" and "somewhat dangerous," respectively. The original fifth category "highly dangerous" was maintained and represents the third category of the dependent variable (Table 4).

For multiple reasons, the multinomial logistic regression (MNR) was the choice of the parametric model. First, one can think of the MNR as an ordered model, which is based on the adjacent approach to comparison. Therefore, the

\footnotetext{
${ }^{7}$ Lechowaska (2018) identified age, gender, physical location, flood characteristics, residence characteristics, size of consequence, range of impact, direct and indirect experience, demographic and socioeconomic characteristics, information, cultural-historical context, religious, and political context as risk perception factors.
} 
Table 1 Respondents' perception of being harmed by a particular natural hazard (in \%). Source Babessi flood data by Pohlman (2015)

\begin{tabular}{llllclc}
\hline & $\begin{array}{l}\text { Not } \\
\text { dangerous }\end{array}$ & $\begin{array}{l}\text { Slightly } \\
\text { dangerous }\end{array}$ & $\begin{array}{l}\text { More or less } \\
\text { dangerous }\end{array}$ & $\begin{array}{l}\text { Somewhat } \\
\text { dangerous }\end{array}$ & $\begin{array}{l}\text { Highly } \\
\text { dangerous }\end{array}$ & $\begin{array}{l}\text { Mean on 5-step likert } \\
\text { scale }\end{array}$ \\
\hline Flash flood & 7.5 & 12.6 & 14.6 & 17.4 & 47.8 & 3.86 \\
Storm & 9.9 & 13.0 & 18.2 & 28.1 & 30.8 & 3.57 \\
Drought & 30.5 & 15.5 & 17.4 & 18.3 & 18.3 & 2.78 \\
Earthquake & 76.2 & 11.9 & 5.2 & 2.0 & 4.8 & 1.47 \\
Landslide & 69.0 & 15.1 & 10.3 & 4.8 & 0.8 & 1.53 \\
\hline
\end{tabular}

$n=253$; Likert scale ranging from $1-5,1=$ not dangerous, and $5=$ highly dangerous

Table 2 Predictors of flood risk perception

\begin{tabular}{|c|c|}
\hline Variables & Description \\
\hline \multicolumn{2}{|c|}{ Socioeconomics, demography \& gender } \\
\hline Age & Age of respondent (in years) \\
\hline Sex & Sex of respondent $(0=$ male; $1=$ female $)$ \\
\hline Household size & Household size (in household members) \\
\hline Household owns land & If the respondent owns land $(0=y e s ; 1=$ no $)$ \\
\hline Household owns house & If household owns a house $(0=y e s, 1=$ no $)$ \\
\hline Income is diversified & If the respondent has a diversified income portfolio $(0=y e s, 1=$ no $)$ \\
\hline \multicolumn{2}{|c|}{ Mental models \& worldviews } \\
\hline Religion & Religious affiliation of respondent $(0=$ Christian, $1=$ Moslem $)$ \\
\hline Literate & Educational level $(0=$ yes, $1=$ no $)$ \\
\hline Household owns phone & If the family owns a phone $(0=y e s, 1=$ no $)$ \\
\hline \multicolumn{2}{|c|}{ Culture \& social construct } \\
\hline Head of household & If respondent is the head of the household $(0=y e s, 1=$ no $)$ \\
\hline Informal leader & If respondent has any leadership position in a self-help group $(0=y e s, 1=$ no $)$ \\
\hline Member in group & If respondent is an active member in any self-help group ( $0=$ yes, $1=$ no) \\
\hline \multicolumn{2}{|l|}{ Trust } \\
\hline Received disaster relief & If the family has received disaster relief at least once $(0=y e s, 1=$ no $)$ \\
\hline Received informal help & If the family was assisted by its informal social network at least once $(0=y e s, 1=$ no) \\
\hline \multicolumn{2}{|l|}{ Placement \& experience } \\
\hline Years resident & For how long has the respondent lived in Babessi (in years) \\
\hline Flood victim of 2012 & If the respondent's family was a flood victim or not in 2012 ( $0=$ yes; $1=$ no) \\
\hline Number of disasters & Disasters the family has experienced from 2012-2015 (number) \\
\hline
\end{tabular}

MNR applies to the intrinsic order implied by the dependent variable. Second, the adjacent approach of the MNR is the preferred approach when individual categories are of theoretical interest and/or there is a middle category in the ordinal scale. Third, the MNR does not apply the proportional odds assumption to any of the predictors (Fullerton 2009). Let us consider, for instance, the predictor flood victim in 2012 (yes, no). It is plausible to assume that those who were not flood victims perceive floods as not or slightly dangerous. Given that the response to the risk perception of flood victims will not go through a sequence of stages (from "not or slightly dangerous" to "dangerous" to "highly dangerous"), the adjacent approach is the most appropriate for this type of ordinal outcome.

Generally, the MNR is used to predict the probability of category membership based on multiple predictors. The output from a MNR is typically presented as a series of comparisons with a single baseline group, which is here the category "not or slightly dangerous." The model is summarized as follows: 
Table 3 Frequency statistics of predictors. Source Babessi flood data by Pohlman (2015)

\begin{tabular}{|c|c|c|c|c|c|}
\hline & Number & Percentage & & Number & Percentage \\
\hline Age of respondent & & & Religious affiliation of respondent & & \\
\hline $15-30$ & 72 & 28.5 & Christian & 206 & 81.4 \\
\hline $31-45$ & 93 & 36.8 & Muslim & 43 & 17.0 \\
\hline $46-60$ & 54 & 21.8 & Other & 4 & 1.6 \\
\hline \multirow[t]{2}{*}{$\geq 61$} & 34 & 13.4 & & & \\
\hline & & & Household owns at least one phone & & \\
\hline Sex of respondent & & & Yes & 210 & 83.0 \\
\hline Male & 96 & 37.9 & No & 43 & 37.0 \\
\hline \multirow[t]{2}{*}{ Female } & 157 & 62.1 & & & \\
\hline & & & Respondent is a leader in a self-help group & & \\
\hline Head of household & & & Yes & 80 & 31.6 \\
\hline Yes & 143 & 56.5 & No & 173 & 68.4 \\
\hline \multirow[t]{2}{*}{ No } & 110 & 43.5 & & & \\
\hline & & & Respondent is a member in a self-help group & & \\
\hline Household size & & & Yes & 181 & 72.5 \\
\hline $1-3$ & 20 & 7.9 & No & 72 & 28.5 \\
\hline $4-6$ & 87 & 34.4 & & & \\
\hline $7-9$ & 93 & 36.8 & Household received at least once disaster relief & & \\
\hline \multirow[t]{2}{*}{$\geq 10$} & 53 & 21.0 & Yes & 95 & 37.5 \\
\hline & & & No & 158 & 62.5 \\
\hline \multicolumn{6}{|l|}{ Household owns land } \\
\hline Yes & 193 & 76.3 & Household received help from self-help group & & \\
\hline \multirow[t]{2}{*}{ No } & 60 & 23.7 & Yes & 34 & 23.4 \\
\hline & & & No & 219 & 86.6 \\
\hline \multicolumn{6}{|l|}{ Household owns house } \\
\hline Yes & 203 & 80.2 & Duration of respondent's residence in Babessi & & \\
\hline \multirow[t]{2}{*}{ No } & 50 & 19.8 & $0-15$ years & 30 & 11.9 \\
\hline & & & $16-30$ years & 81 & 32.0 \\
\hline Income is diversified & & & $31-45$ years & 75 & 29.6 \\
\hline Yes & 146 & 57.7 & $\geq 46$ & 63 & 26.5 \\
\hline \multirow[t]{2}{*}{ No } & 107 & 42.3 & & & \\
\hline & & & If respondent was a flood victim in 2012 & & \\
\hline Education (literacy) of respondent & & & Yes & 138 & 54.5 \\
\hline None & 129 & 51.0 & No & 115 & 45.5 \\
\hline Primary school & 60 & 23.7 & & & \\
\hline Middle school & 53 & 21.0 & Number of disasters experienced from 2012-2015 & & \\
\hline \multirow[t]{2}{*}{ High school } & 11 & 4.3 & 0 & 12 & 4.7 \\
\hline & & & 1 & 70 & 27.7 \\
\hline Illiterate & 129 & 54.5 & 2 & 117 & 46.2 \\
\hline \multirow[t]{2}{*}{ Literate } & 115 & 45.5 & 3 & 40 & 15.8 \\
\hline & & & 4 & 14 & 5.5 \\
\hline
\end{tabular}

$n=253$

Flood risk perception:

$$
\left\{\begin{array}{c}
0=\text { not or sligtly dangerous } \\
1=\text { dangerous } \\
2=\text { highly dangerous }
\end{array}\right\}=f\left(\alpha+\beta X_{i}, \varepsilon\right)
$$

whereby $\alpha=$ intercept, $\beta=$ regression coefficient, $X_{i}=$ predictors, and $\varepsilon=$ error term.

The model building process involves several stages. First, predictors are examined for multicollinearity using 
Table 4 Dependent ordinal variable-Risk perception of being harmed by another flood Source: Babessi flood data by Pohlman (2015)

\begin{tabular}{lcc}
\hline Risk perception & Number & Percent \\
\hline Not or slightly dangerous & 42 & 17.7 \\
Dangerous & 79 & 33.3 \\
Highly dangerous & 116 & 49.0 \\
\hline
\end{tabular}

$n=237$, victims $=131$, non-victims $=106$. In the multinomial logistic regression (see Sect. 4), 16 observations are missing, 7 due to outliers and 9 due to missing data. This table refers to the sample used in the regression

the variance inflation factors (VIFs). The VIFs for all explanatory variables were below the conservative critical value of 3. Therefore, we can safely ignore the issue of multicollinearity. Furthermore, it is desirable to use a model that not only fits the data but is also specified with as few predictors as possible (Best and Wolf 2010). The number of observations per predictor in the model is 14 , which is sufficiently above the recommended minimum of 10 (Vittinghoff and McCulloch 2007).

Second, although the MNR is robust against outliers, predictors were examined using appropriate diagnostics. Schendera (2014) suggests running separate binary logistic regressions. As the category "not or slightly dangerous" was selected as reference category, it was compared to the two other categories in two binary logistic regressions. The studentized residuals were saved and seven observations with a residual greater than \pm 2 were marked as possible outliers.

Third, the MNR was run with all observations and without the observations containing possible outliers. If the accuracy rate of the model increases by at least two percentage points, Schendera (2014) suggests using the reduced model without the outliers. Since this was the case, we decided to use the reduced sample (see Table 4) in the MNR to avoid biased coefficient estimates or very large standard errors. Another nine observations were dropped from the regression because of missing data. Finally, we ran the reduced MNR using bootstrapping to obtain robust estimates despite the relatively small sample.

\section{Perception of Flood Risk-Results and Discussion}

In the following, the MNR is presented focusing on the three categories for respondents' perceived flood risk: (1) "not or slightly dangerous"; (2) "dangerous"; and (3) "highly dangerous." The first category functions as reference category. The MNR is based on 237 observations (see Table 4).

\subsection{Model Fit}

The regression diagnostics for the goodness-of-fit, except for the Pearson Chi-square, are all within standard range. The maximum likelihood ratio Chi-square of 274.639 is significant at the $1 \%$ level, indicating that the current model (compared to the null model) significantly increased our ability to predict risk perception. The Pearson Chisquare is significant, portending that the model does not fit the data well (Schendera 2014). Nevertheless, Bühl (2012) points out that these asymptotic tests assume large expected counts in the classification cells, which is not the case here due to the rather small sample size (see Table 5). Furthermore, this situation arises almost any time when having continuous predictors in the MNR. Therefore, it is recommended not to put too much confidence in the result of the Pearson Chi-square.

The pseudo R-squares range between $67.5 \%$ (Nagelkerke-pseudo $\mathrm{R}^{2}$ ), $58.8 \%$ (Cox \& Snell-pseudo $\mathrm{R}^{2}$ ), and $43.3 \%$ (McFadden-pseudo $\mathrm{R}^{2}$ ). A pseudo- $\mathrm{R}^{2}$ between $20 \%$ and $40 \%$ can already be considered a good model fit (Schendera 2014). Overall, the model classifies $81 \%$ of all observations and between $71 \%$ and $87 \%$ of the predicted risk perception responses correctly (Table 5 ).

\subsection{Discussion of the Flood Risk Perception}

Table 6 depicts the MNR results with regard to flood risk perception. The discussion thereof is organized along the major paradigms theorizing risk perception.

\subsubsection{Socioeconomics, Demography, and Gender}

Ownership of crucial livelihood assets is connected with risk perception (Qasim et al. 2015). The coefficient for land ownership is positive and significant. Most households try to be at least partly self-sufficient with regard to food production; therefore land is an important asset. Obviously, a flood can cause severe damage to this asset, eventually lasting for more than one harvesting season. Interestingly, the risk perception of households that own a house is not unanimous. The coefficient is positive for the risk perception category "dangerous" and negative for "highly dangerous" (although only at the 10\% level). This is in line with findings of Mertens et al. (2018) for Uganda. Households that had lost their houses in 2012 to the flood received disaster relief and rebuilt stronger houses with a sturdy stone base (Fig. 2b). Qualitative research revealed that these households seemed now to assume that they were no longer vulnerable to future flood hazards. House owners 
Table 5 Classification of correctly predicted observations for flood risk perception. Source Babessi flood data by Pohlman (2015)

\begin{tabular}{|c|c|c|c|c|}
\hline \multirow[t]{2}{*}{ Observed } & \multicolumn{3}{|c|}{ Predicted } & \multirow[t]{2}{*}{ Percent correct } \\
\hline & 1 & 2 & 3 & \\
\hline $1=$ Flood is not or slightly dangerous & 30 & 3 & 9 & 71.4 \\
\hline $2=$ Flood is dangerous & 2 & 62 & 15 & 78.5 \\
\hline $3=$ Flood is highly dangerous & 4 & 11 & 101 & 87.1 \\
\hline Overall percent correct predicted & & & & 81.4 \\
\hline
\end{tabular}

$n=237$

are, however, 5.5 times more likely to perceive floods as dangerous instead of not or slightly dangerous. As pointed out earlier, victims whose houses had been damaged but not destroyed in the 2012 flood had received hardly any disaster relief to reinforce the foundations of their houses. Thus, they may still perceive their houses being at risk to future floods. These results are in line with the negative coefficient for those who have received governmental disaster relief in 2012, the odds of perceiving floods as "not or slightly dangerous" increase by around 19\%. This may also reflect their positive experience with an earlier governmental disaster relief intervention. As mentioned by one flood victim: "Building a house is not easy. But seeing it destroyed by a flood is even more frustrating. I was very devastated when my house was destroyed by the 2012 [Babessi] floods. I am however very grateful to the stones given to us by the SDO. You can see for yourself that the foundation of my new house is very high. I am sure that any future floods will not affect my house again. But no one knows [...] maybe the next one [flood] will rise above this foundation. I do not want to imagine what will happen" (Peter, household head and flood victim in Babessi).

The predictors "age" and "income is diversified" are significant for the flood risk perception "highly dangerous" only. The coefficient for age is negative. This indicates that with one year increase in age, the odds of perceiving floods as "highly dangerous" as compared to "not or slightly dangerous" is reduced by about $13 \%$. Counterintuitively, households with a diversified income perceive the risk of floods being "highly dangerous," 7 times more likely as compared to "not or slightly dangerous." Income diversification is, after all, identified as a major risk management ex ante strategy employed by many rural poor in large parts of sub-Saharan Africa (Seo 2010; Gebre-Egziabher et al. 2018). Molua (2011) found, however, that many income sources of the rural poor remain tied to their major occupation and the well-being of the community they reside in. He further emphasized that a natural hazard and disaster such as a flood can damage the major income source and thus has a devastating impact on all sources of income. In other words, even a well-diversified income portfolio of the rural poor may still be vulnerable to a significant covariate risk, namely natural hazard-related disasters. Diversification of income normally involves being in contact with the outside world, for example, when being engaged in transportation or as a (petty) trader. Therefore, we may also tentatively interpret this result such that these persons are better informed through social interaction. This in turn may change the mental model such that risk perception is heightened (see also the results related to "household owns at least one phone"). The predictor "household size" is negative for both expressions of flood risk perception, but significant for "dangerous" only. With each additional household member, the odds that risk is perceived as "dangerous" (as compared to "not or slightly dangerous") is reduced by $33 \%$. Traditionally - and especially in rural areas where the educational level is lower-larger families have been considered as an effective risk managing mechanism (Sooryamoorthy and Chetty 2015). First, family members function as nonwage-earning workers and financial supporters, which possibly makes coping with disasters easier. Second, bigger families have greater opportunity to diversify their income sources, which may help in managing risks - not to forget the parental old-age risk. This may explain the result.

Contrary to our expectation, the predictor "sex" was not significant. With regard to the sex of the respondent, empirical results are mixed. A number of scholars contend that women tend to rate the risk associated to natural hazards higher than men (Ho et al. 2008). The plausible explanation given relates to the potentially greater vulnerability of women in combination with their lack of empowerment and resources. Pohlmann (2015) found no gender link, hypothesizing that the flood disaster did not discriminate between women and men in Babessi, Cameroon. 
Table 6 Multinomial logistic regression results-Flood risk perception. Source Babessi flood data by Pohlmann (2015).

\begin{tabular}{|c|c|c|c|c|c|}
\hline \multirow[b]{4}{*}{ Predictors } & \multirow[b]{4}{*}{ Reference } & \multicolumn{4}{|c|}{$\begin{array}{l}\text { Respondents' Risk Perception of } \\
\text { Being Harmed by Another Flood }\end{array}$} \\
\hline & & \multicolumn{2}{|c|}{ Dangerous } & \multicolumn{2}{|c|}{ Highly Dangerous } \\
\hline & & $\beta$ & Odds & $\beta$ & Odds \\
\hline & & & Ratio & & Ratio \\
\hline \multicolumn{6}{|c|}{ Socioeconomics, demography, and gender } \\
\hline Age (in years) & & $\begin{array}{l}-0.020 \\
(0.029)\end{array}$ & 0.980 & $\begin{array}{r}-0.178^{* * *} \\
(0.036)\end{array}$ & 0.873 \\
\hline Sex (male) & (female) & $\begin{array}{r}0.667 \\
(0.734)\end{array}$ & 1.948 & $\begin{array}{l}-0.369 \\
(0.700)\end{array}$ & 0.692 \\
\hline Household size (members) & & $\begin{array}{r}-0.268 * * * \\
(0.074)\end{array}$ & 0.765 & $\begin{array}{l}-0.030 \\
(0.050)\end{array}$ & 0.970 \\
\hline Household owns land (yes) & (no) & $\begin{array}{r}1.600 * * \\
(0.685)\end{array}$ & 4.955 & $\begin{array}{r}2.489 * * * \\
(0.695)\end{array}$ & 12.048 \\
\hline Household owns house (yes) & (no) & $\begin{array}{r}1.718^{* *} \\
(0.839)\end{array}$ & 5.574 & $\begin{array}{r}-1.242^{*} \\
(0.687)\end{array}$ & 0.289 \\
\hline Income is diversified (yes) & (no) & $\begin{array}{l}-0.411 \\
(0.569)\end{array}$ & 0.663 & $\begin{array}{r}1.948 * * * \\
(0.577)\end{array}$ & 6.978 \\
\hline \multicolumn{6}{|l|}{ Mental models } \\
\hline Religion (Christian) & (Muslim) & $\begin{array}{r}1.821^{* * *} \\
(0.706)\end{array}$ & 6.175 & $\begin{array}{r}0.772 \\
(0.636)\end{array}$ & 2.164 \\
\hline Literate (yes) & (no) & $\begin{array}{r}-2.914 * * * \\
(0.815)\end{array}$ & 0.054 & $\begin{array}{r}-3.273 * * * \\
(0.784)\end{array}$ & 0.038 \\
\hline Household owns phone (yes) & (no) & $\begin{array}{r}0.138 \\
(0.667)\end{array}$ & 1.148 & $\begin{array}{r}1.973 * * * \\
(0.753)\end{array}$ & 7.192 \\
\hline \multicolumn{6}{|l|}{ Culture and social construct } \\
\hline Head of household (yes) & (no) & $\begin{array}{r}2.685 * * * \\
(0.807)\end{array}$ & 14.663 & $\begin{array}{r}2.425 * * * \\
(0.822)\end{array}$ & 11.302 \\
\hline Respondent is informal leader (yes) & (no) & $\begin{array}{r}1.332 * \\
(0.703)\end{array}$ & 3.787 & $\begin{array}{r}1.439 * * \\
(0.658)\end{array}$ & 4.215 \\
\hline Respondent is group member (yes) & (no) & $\begin{array}{r}0.321 \\
(0.627)\end{array}$ & 1.379 & $\begin{array}{r}0.097 \\
(0.593)\end{array}$ & 1.101 \\
\hline \multicolumn{6}{|l|}{ Trust } \\
\hline Received disaster relief (yes) & (no) & $\begin{array}{l}-0.499 \\
(0.573)\end{array}$ & 0.607 & $\begin{array}{r}-1.189^{* *} \\
(0.566)\end{array}$ & 0.305 \\
\hline Received informal help (yes) & (no) & $\begin{array}{r}0.410 \\
(0.750)\end{array}$ & 1.507 & $\begin{array}{r}0.599 \\
(0.763)\end{array}$ & 1.820 \\
\hline \multicolumn{6}{|l|}{ Placement and experience } \\
\hline Years resident in Babessi & & $\begin{array}{l}-0.340 \\
(0.023)\end{array}$ & 0.967 & $\begin{array}{r}0.034 \\
(0.025)\end{array}$ & 1.035 \\
\hline Flood victim of 2012 (yes) & (no) & $\begin{array}{r}-1.941 * * \\
(0.682)\end{array}$ & 0.144 & $\begin{array}{r}-1.549 * \\
(0.677)\end{array}$ & 0.213 \\
\hline Number of disasters (2012-2015) & & $\begin{array}{l}-0.431 \\
(0.326)\end{array}$ & 1.539 & $\begin{array}{l}-0.493 \\
(0.327)\end{array}$ & 0.611 \\
\hline Intercept & & $\begin{array}{r}0.581 \\
(1.666) \\
\end{array}$ & & $\begin{array}{r}5.792 * * * \\
(1.484) \\
\end{array}$ & \\
\hline
\end{tabular}

$n=237$; Reference category $=$ No or slight danger perceived regarding flood hazard

Bootstrapped unstandardized logit coefficients are presented (with standard errors in parentheses).

The significance test is computed with the Wald Chi-square test

***Significant at $1 \%$ level

**Significant at $5 \%$ level

*Significant at $10 \%$ level 


\subsubsection{Mental Models}

A literate respondent ( $46 \%$ of the sample), as opposed to an illiterate, is on average $95 \%$ less likely to perceive the flood risk as "dangerous" or "highly dangerous." Moreover, the odds that literate individuals, in comparison to illiterate people, will perceive floods only as "dangerous" and not as "highly dangerous" is $42 \%$ higher. This is a strong indication for the power of education regarding mental models or worldviews (Lechowaska 2018). It could also point at an interaction effect similar to the one pointed out by Brody and Highfield (2005) for the U.S. but in reverse: literacy may be plausibly linked to higher income and thus a lower risk perception.

The predictor religion was only significant for the flood risk perception "dangerous." The odds of Christians as compared to Muslims to perceive floods as "dangerous" rather than "not or slightly dangerous" are 6 times higher. Bang (2008) found a similar result when investigating the Lake Nyos disaster in Cameroon. This result could imply that Christians link natural hazard-related disasters with a punishing God, especially when a reference is made to the biblical flood narrative as Wagner (2010) suggests. The Muslim population may have taken a less fatalist position, namely "Allah helps those who help themselves" (Schipper 2010, p. 388). ${ }^{8}$ Nevertheless, in the specific case of Cameroon, it appears more plausible to interpret this result based on location. Christian and Muslim residential areas in Babessi are mostly divided in such a way that Christians rather live in the valley and Muslims in the hills, where the latter rear cattle. In this respect, the Muslims may have been indeed less affected by floods because of locational factors.

The predictor "household owns at least one phone" (83\% of the sample) is significant for the flood risk perception "highly dangerous" only. This predictor was included in the analysis as a rough proxy of connectedness to the outside world and to information (for example, on natural hazards or disaster relief measures). It seems that being connected to information initiates cognitive mediating processes as indicated by Rogers and Prentice-Dunn (1997), and thus changes the mental model such that risk perception is heightened. Those with phones are 7.2 times more likely to perceive floods as "highly dangerous" rather than "not or slightly dangerous." A phone also increases the chances of the owner to be informed of the effects of similar floods in other places, which can influence flood risk perception.

\footnotetext{
${ }^{8}$ It is worth mentioning that the same people, who believe in a Christian or Muslim God, also adhere to ancestral beliefs. Thus, one cannot literally differentiate between believing in an "important" god and believing in the ancestral "gods."
}

\subsubsection{Culture and Social Construct}

The coefficient sign for the social construct predictor "head of household" is positive. A head of household, as compared to a regular household member, is 14 times (respectively 11 times) more likely to perceive the flood risk as "(highly) dangerous" as compared to "not or slightly dangerous." The hierarchical role of a head of household may entail being responsible for the well-being of his/her household members. Although the empirical support for the role of rank and role in risk perception was meager (Oltedal et al. 2004; Johnson and Swedlow 2021), our results show the opposite. The results related to self-help further substantiate this statement. In developing countries, especially in more rural regions, citizens often perceive the state as absent or reluctant to provide public goods and services. Therefore, the culture of self-help and mutual aid is widespread to increase community resilience. Community resilience is closely linked to disaster risk reduction (Schelfaut et al. 2011). The odds of an informal leader of a self-help or mutual aid group as compared to a person without a leadership function to perceive floods as "(highly) dangerous" rather than "not or slightly dangerous" are about 4 times higher. This result may be associated with their selective awareness of having a social responsibility for the group members. These traditional risk coping mechanisms, however, perform best when mitigating idiosyncratic risks (for example, health risks) but are usually overstrained with mass disasters, such as natural hazards (Schrieder 1996; Balgah et al. 2015). Therefore, it appears to be a plausible result that group membership in traditional self-help or mutual aid groups does not significantly influence risk perception because members of selfhelp and mutual aid groups realize that these types of protective action neither improve individual nor community resilience notably in the wake of floods.

\subsubsection{Trust}

Respondents who had benefited from governmental disaster relief after the 2012 flood displayed a lower likelihood to perceive floods as "highly dangerous." This is a strong indication for the benefit of public transfers, which are resulting in more trust into the state and local government (even though corruption was reported). Nevertheless, trust in authorities may also create a false sense of safety (Bonß 1997; Lechowska 2018).

The predictor respondent received informal help was not significant. As mentioned above, self-help and mutual aid groups are functionally constrained when all group members are hit by a mass disaster and are simultaneously in need of assistance. This is in line with UNISDR (2009) stating that disasters disrupt the ability of affected 
communities to cope with the effects using own resources. Therefore, they may feel confident that their group membership buffers idiosyncratic risks but not mass disasters. Indeed, only about $25 \%$ of the respondents had benefitted from informal social transfers after the 2012 flood.

\subsubsection{Location and Experience}

Although one would anticipate that previous hazard experience leads to a higher perceived risk, our results rather support Peacock et al. (2005) and Halpern-Felsher et al. (2001). People with previous hazard experience may think this has made them less amenable and vulnerable to future events and their negative impacts. Victims of the flood in Babessi in 2012 show a substantially reduced likelihood to perceive the flood risk as "dangerous" or "highly dangerous" (minus $85 \%$ or minus $78 \%$, respectively). Nevertheless, the odds for somebody who was a flood victim in 2012 as compared to not are $32 \%$ more likely to select "highly dangerous" as compared to "dangerous." This result is consistent with the "number of disasters experienced from 2012-2015"; this predictor shows a negative sign too, albeit not significant. Mertens et al. (2018) found for Uganda and the risk of landslides that those at risk may fall into what has been called a "fatalism trap." They fear the disastrous effect of the natural hazard but do not believe that something can be done about it. They continue to say that this finding is rather new to the literature on protective behavior in the presence of natural hazards, but not to the literature on the PMT as a whole. In our case study, it is possible that the construction of houses with higher foundations after the 2012 flood could have moderated the risk perception of victims too.

\subsubsection{Implications for the Adaptive Capacity of those at Risk to Reduce the Risk from Floods}

The Sendai Framework for Disaster Risk Reduction 2015-2030 recognizes that the state has the primary role to reduce disaster risk but that an all-of-society engagement is important for implementing risk reduction measures at the aggregate and the individual levels (UNISDR 2015). Obviously, there exist structural and non-structural mitigation measures against floods at the state and individual levels. While non-structural mitigation measures may be available to many of those at risk (for example, self-help, income diversification, and so on), only a limited number of the structural measures (for example, sturdy house bases, small surface farm dams, and so on) are technically or financially feasible for potential victims of floods in rural areas of developing countries such as Cameroon.

In line with the PMT (Rogers and Prentice-Dunn 1997), the decision of those at risk of flood hazards in adopting precautionary measures to protect themselves appears to be linked to four broad perceptual processes: risk perception, coping appraisal, disaster experience appraisal, and administrative measures appraisal. When risk perception and coping appraisal are high, (potential) flood victims seem to be more likely to engage in protective action (Grothmann and Reusswig 2006; Bradford et al. 2012). Results from Europe further reveal that risk perception is a reliable predictor in terms of motivating potential victims of floods to adopt measures that require small investments in the form of efforts and costs but not high levels of investment (Koerth et al. 2013). This is especially true in the contemplative stage as reported by Gebrehiwot and van der Veen (2015) for drought victims from Ethiopia. Delfiyan et al. (2021) support this notion with regard to drought risks in Iran, stating that it is important to provide effective but low-cost responses by suggesting precautionary measures that require little time and money. Yet, the response efficacy must be given, especially for disaster victims in action (Gebrehiwot and van der Veen 2015). However, the likelihood to invest in risk management measures decreases when the (potential) victim has high confidence in the state to take appropriate action (Grothmann and Reusswig 2006).

Our results suggest that the majority of those at risk from floods are organized in self-help and mutual-aid groups. However, this non-structural risk mitigation measure is not very efficient for place-based mass disasters such as floods. At the same time, formal insurance systems are absent. Given that the response efficacy vis-á-vis floods of self-help groups could be improved, for instance through regional integration, there appears to be great potential for this form of risk management. Income diversification is known as risk management tool of those at risk. However, it may not function in view of mass disasters because many income sources of the rural poor remain tied to the major occupation and the well-being of the community they reside in (Molua 2011).

Here the state could proactively invest in regional development that is not affected by the place-specific hazard, for example, through creating low-threshold jobs in regional governmental offices. Furthermore, those responsible for designing and implementing flood risk information and management plans should ensure that they capture the knowledge from experienced flood victims (Bradford et al. 2012). The results of our study suggest integrating those with informal leadership roles in this process, as their risk perception is more pronounced due to their responsibility for the well-being of fellow residents. This further implies that flood risk information and management plans must be rather place-specific (Di Baldassarre et al. 2010). The Ministry of Territorial Administration and Decentralization together with the Directorate for Civil Protection 
are the responsible public authorities in Cameroon for disaster management. While the majority of the Cameroonian population owns a smart phone, there exists no emergency warning and information app yet. This could be a structural investment at the state level, which is low cost for those at risk (Khandaker et al. 2012).

\section{Conclusion}

The majority of natural hazards occur in developing countries and the related human suffering, especially in rural areas, is particularly high. However, studies on risk perception are rather few. In fact, perception of flood risk is often not available or overlooked when developing flood risk management strategies. This constitutes a disconnection between the people at risk from floods and the state, which has detrimental effects on community resilience with regard to flood hazards (Bradford et al. 2012). We make a contribution to narrowing this knowledge gap with an empirical case study of a flash flood disaster that occurred in 2012, in the rural town of Babessi, in the Northwest Region of Cameroon.

Heads of households and respondents with an informal leadership function displayed a higher likelihood to evaluate flood disasters as (highly) dangerous. We associate this result to their hierarchical social role as provider, either in the household or in informal self-help groups. The selective awareness of the social responsibility for the wellbeing of a group of people may lead to a heightened risk perception. Land is a most valuable asset in developing countries, where most households aim to maintain some degree of self-sufficiency with regard to food provision. A flood can destroy this asset and the crops growing on it not only in the short term but even for a longer period of time. Thus, it is not surprising that respondents who own land perceive the flood risk as (highly) dangerous.

Literacy was found to reduce the flood risk perception. Furthermore and counterintuitively, flood victims of 2012 display a substantially reduced likelihood to perceive floods as (highly) dangerous. Thus it seems plausible to assume that better educated people and people with prior exposure to a flood hazard may have developed different mental models and worldviews. It could also be indicative of a higher level of self-efficacy.

A number of factors turned out significant in only one of the two displayed risk perception categories. Worth highlighting is the effect of the public relief on risk perception. Respondents who had benefitted from governmental disaster relief in 2012 displayed a lower likelihood to perceive floods as highly dangerous in 2015 . This is a strong indication of the benefit of public transfers, which is resulting in more trust in the state. Nevertheless, trust in authorities may also create a false sense of safety (Mertens et al. 2018). Thus, in addition to implementing policies that foster the adaptive capacity of (potential) flood victims in response to their risk perception, it is also important to avoid policies that could have a detrimental effect on a possible decision to adopt precautionary measures to protect themselves.

Some limitations abound in this study. There is ample evidence that flood risk management policies have been known to fail or be adversely affected when the subjective and contextualized nature of risk perception is overlooked (Bradford et al. 2012). First of all, while this article highlights the place-based context of risk perception, it could only indirectly link perception to private and public risk management strategies. Protective action differs however according to whether people are aware of their own risk or not. Depending on the degree of risk awareness in combination with a false sense of security, the impact of public information, warning, and risk management campaigns could fizzle out. Research on the explicit link between flood risk perception, public dissemination of related information, and risk management measures, could not only lead to increased trust in public authorities but also enhance the capacity to respond to floods and increase community resilience. Second, whether or not a household owns a phone was used in our study as a rough proxy for the connectedness of the household to the outside world and to information on flood risks. Yet, it is plausible to assume that those at risk of floods use various information channels and attach different degrees of confidence to them. What works and what does not in terms of information channels should be further investigated. Third, our research context, that is, risk perception of flood disasters in a rural town in a developing country is quite specific and thus, the generality of our results is unclear. Fourth, Schipper (2010) argues that risk perception with regard to climate change decisively determines the willingness to take precautionary action through a wide variety of beliefs and practices. Therefore, a differentiated analysis is necessary with regard to whether faith and religion can promote proactive behavior or fatalistic passivity. Fifth, we think it would be especially fruitful to investigate not only the flood risk perception of those at risk of a flood disaster but also of those who are not at risk and of the policymakers responsible for information and risk management campaigns. Finally, we could not determine the extent to which those at risk from flooding feel prepared or feel responsible for taking protective action (Bradford et al. 2012). Thus, it would be helpful to do a self-assessment study on how those at risk of flooding feel prepared for the next flood and feel responsible for taking protective action at individual and community levels. 
Continuous research is thus necessary to derive more robust results regarding the factors influencing flood risk perception and resulting protective action in a developing country like Cameroon, where the occurrence of floods are escalating; and to identify tendencies that can facilitate flood risk management across multiple developing countries

Open Access This article is licensed under a Creative Commons Attribution 4.0 International License, which permits use, sharing, adaptation, distribution and reproduction in any medium or format, as long as you give appropriate credit to the original author(s) and the source, provide a link to the Creative Commons licence, and indicate if changes were made. The images or other third party material in this article are included in the article's Creative Commons licence, unless indicated otherwise in a credit line to the material. If material is not included in the article's Creative Commons licence and your intended use is not permitted by statutory regulation or exceeds the permitted use, you will need to obtain permission directly from the copyright holder. To view a copy of this licence, visit http://creativecommons. org/licenses/by/4.0/.

\section{References}

Ahsan, D.A. 2011. Farmers' motivations, risk perceptions and risk management strategies in a developing economy: Bangladesh experience. Journal of Risk Research 14(3): 325-334.

Aka Tangan, P., P. Azinwi Tamfuh, A. Magha Mufur, E.L. Tanko Njiosseu, J. Nfor, A.F. Mefire, and D. Bitom. 2018. Communitybased approach in the prevention and management of flood disasters in Babessi sub-division (Ndop Plain, North West Cameroon). Journal of Geoscience and Environment Protection 6: 211-228.

Alexander, D.E. 2000. Confronting catastrophe. New York: Oxford University Press.

Alexander, D.E. 2009. Natural hazards. In Geography - Encyclopedia of life support systems (EOLLS), vol 1, ed. M. Sala, 364-387. Paris: Eolss Publishers.

Backhaus, K., B. Erichson, R. Weiber, and W. Plinke. 2016. Multivariate analysis methods (Multivariate Analysemethoden). Berlin: Springer (in German).

Balgah, R.A. 2012. Explorative research trip. Mimeo. Bamenda, Cameroon: University of Bamenda.

Balgah, R.A., G. Buchenrieder, and I.N. Mbue. 2015. When nature frowns: A comprehensive impact assessment of the 2012 Babessi floods on people's livelihoods in rural Cameroon. Journal of Disaster Risk Studies 7(1): 1-8.

Bang, H.N. 2008. Social vulnerability and risk perception to natural hazards in Cameroon two decades after the Lake Nyos gas disaster: What future prospect for the displaced disaster victims? Presentation during the 2008 Summer Academy for Social Vulnerability. Bonn, Germany: United Nations University, Institute for Environment and Human Security (UNU-EHS).

Below, R., A. Wirtz, and D. Guha-Sapir. 2009. Disaster category classification and peril terminology for operational purposes. Working Paper. Louvain, Belgium: Centre for Research on the Epidemiology of Disasters (CRED), University Catholique de Louvain. https://www.cred.be/node/564. Accessed 21 Feb 2019.

Benson, C., and E.J. Clay. 2004. Understanding the economic and financial impacts of natural disasters. Disaster Risk Management Series No. 4. Washington, DC: World Bank Publications.
Best, H., and C. Wolf. 2010. Logistic regression (Logistische Regression). In Manual of social science data analysis (Handbuch der sozialwissenschaftlichen Datenanalyse), ed. C. Wolf, and H. Best, 827-854. Wiesbaden, Germany: Springer (in German).

Birkholz, S., M. Muro, P. Jeffrey, and H.M. Smith. 2014. Rethinking the relationship between flood risk perception and flood management. Science of the Total Environment 478: 12-20.

Birkmann, J. 2013. Risk. In Encyclopedia of natural hazards, ed. P.T. Bobrowsky, 856-862. Dordrecht: Springer.

Boholm, M. 2011. The semantic distinction between "risk" and "danger": A linguistic analysis. Risk Analysis 32(2): 281-293.

Bokwa, A. 2013. Natural hazard. In Encyclopedia of natural hazards, ed. P.T. Bobrowsky, 711-718. Dordrecht: Springer.

Bonß, W. 1996. The return of uncertainty: Socio-theoretical significance of the concept of risk (Die Rückkehr der Unsicherheit: Zur gesellschaftstheoretischen Bedeutung des Risikobegriffs). In Risk research between discipline and interdisciplinarity. From the illusion of security to dealing with uncertainty (Risikoforschung zwischen Disziplinarität und Interdisziplinarität. Von der Illusion der Sicherheit zum Umgang mit Unsicherheit), ed. G. Banse, 165-184. Berlin: Edition Sigma (in German).

Bonß, W. 1997. The social construction of security (Die gesellschaftliche Konstruktion von Sicherheit). In Security in an unsecure society (Sicherheit in der unsicheren Gesellschaft), ed. E. Lippert, A. Prüfert, and G. Wachtler, 21-41. Opladen, Germany: Westdeutscher Verlag (in German).

Botzen, W.J.W., J.C.J.H. Aerts, and J.C.J.M. van den Bergh. 2009. Dependence of flood risk perceptions on socioeconomic and objective risk factors. Water Resources Research 45(10): 1-15.

Bradford, R.A., J.J. O'Sullivan, I.M. van der Craats, J. Krywkow, P. Rotko, J. Aaltonen, M. Bonaiuto, and S. De Dominicis et al. 2012. Risk perception - Issues for flood management in Europe. Natural Hazards and Earth System Sciences 12: 2299-2309.

Bronfman, N.C., P.C. Cisternas, E. López-Vázquez, and L.A. Cifuentes. 2016. Trust and risk perception of natural hazards: Implications for risk preparedness in Chile. Natural Hazards 81(1): 307-327.

Bubeck, P., W.J. Botzen, and J.C. Aerts. 2012. A review of risk perceptions and other factors that influence flood mitigation behavior. Risk Analysis 32(9): 1481-1495.

Buchenrieder, G., J. Brandl, and A.R. Balgah. 2019. Risk perception of those at risk from floods in Babessi, Cameroon (Die Risikowahrnehmung von Überschwemmungen durch Betroffene in Babessi, Kamerun). In The risk - Thoughts about and into the unknown. Interdisciplinary negotiation of the risk phenomenon in the light of Reflective Modernism (Das Risiko - Gedanken übers und ins Ungewisse. Interdisziplinäre Aushandlungen des Risikophänomens im Lichte der Reflexiven Moderne), ed. H. Pelizäus, and L. Nieder, 389-425. Berlin: Springer (in German).

Burns, W.J., and P. Slovic. 2012. Risk perception and behaviors: Anticipating and responding to crises. Risk Analysis 32(4): $579-582$.

Bustillos Ardaya, A., M. Evers, and L. Ribbe. 2007. What influences disaster risk perception? Intervention measures, flood and landslide risk perception of the population living in flood risk areas in Rio de Janeiro state, Brazil. International Journal of Disaster Risk Reduction 25: 227-237.

Bühl, A. 2012. SPSS20: Introduction into modern data analysis (SPSS 20: Einführung in die moderne Datenanalyse). Munich: Pearson Studium (in German).

CRED (Centre for Research on the Epidemiology of Disasters). 2019. EM-DAT (Emergency Database). Disaster criteria. Brussels: CRED, Université Catholique de Louvain. https://www.emdat. 
be/explanatory-notes \& https://emdat.be/glossary. Accessed 5 Feb 2019.

Dake, K. 1991. Orienting dispositions in the perception of risk An analysis of contemporary worldviews and cultural biases. Journal of Cross-Cultural Psychology. 22(1): 61-82.

Dake, K. 1992. Myths of nature: Culture and the social construction of risk. Journal of Social Issues 48(4): 21-37.

Delfiyan, F., M. Yazdanpanah, M. Forouzani, and J. Yaghoubi. 2021. Farmers' adaptation to drought risk through farm-level decisions: The case of farmers in Dehloran County. Southwest of Iran. Climate and Development 13(2): 152-163.

Di Baldassarre, G., A. Montanari, H. Lins, D. Koutsoyiannis, G. Brandimarte, and G. Blöschl. 2010. Flood fatalities in Africa: From diagnosis to mitigation. Geophysical Research Letters 37(22): Article L22402.

Fischhoff, B., P. Slovic, S. Lichtenstein, S. Read, and B. Combs. 1978. How safe is safe enough? A psychometric study of attitudes towards technological risks and benefits. Policy Science 9(2): 127-152.

Floyd, D.L., S. Prentice-Dunn, and R.W. Rogers. 2000. A metaanalysis of research on protection motivation theory. Journal of Applied Social Psychology 30(2): 407-429.

Fondo, S., A.R. Balgah, and T.M. Nij. 2018. Making decisions after floods: A consistency check of drivers across multiple flood types. MOJ Ecology \& Environmental Sciences 3(6): 393-401.

Fullerton, A.S. 2009. A conceptual framework for ordered logistic regression models. Sociological Methods \& Research 38(2): 306-347.

Gebre-Egziabher, F., Seid-Sani, and Biruk-Kemaw. 2018. The role of income diversification on risk management and rural household food security in Ethiopia. Journal of Economics and Sustainable Development 9(9): 15-24.

Gebrehiwot, T., and A. van der Veen. 2015. Farmers prone to drought risk: Why some farmers undertake farm-level risk-reduction measures while others not?. Environmental Management 55(3): 588-602.

Grothmann, T., and F. Reusswig. 2006. People at risk of flooding: Why some residents take precautionary action while others do not. Natural Hazards 38(1-2): 101-120.

Halpern-Felsher, B.L., S.G. Millstein, J.M. Ellen, N.E. Adler, J.M. Tschann, and M. Biehl. 2001. The role of behavioral experience in judging risks. Health Psychology 20(2): 120-126.

Hisali, E., P. Birungi, and F. Buyinza. 2011. Adaptation to climate change in Uganda: Evidence from micro level data. Global Environmental Change 21(4): 1245-1261.

Ho, M.-C., D. Shaw, S. Lin, and Y.-C. Chiu. 2008. How do disaster characteristics influence risk perception? Risk Analysis 28(3): 635-643.

Johnson, B.B., and B. Swedlow. 2021. Cultural theory's contributions to risk analysis: A thematic review with directions and resources for further research. Risk Analysis 41(3): 429-455.

Kates, R.W., and J.X. Kasperson. 1983. Comparative risk analysis of technological hazards: A review. Proceedings of the National Academy of Sciences 80(22): 7027-7038.

Kellens, W., R. Zaalberg, T. Neutens, W. Vanneuville, and P. De Maeyer. 2011. An analysis of the public perception of flood risk on the Belgian coast. Risk Analysis 31(7): 1055-1068.

Kendon, E.J., R.A. Stratton, S. Tucker, J.H. Marsham, S. Berthou, D.P. Rowell, and C.A. Senior. 2019. Enhanced future changes in wet and dry extremes over Africa at convection-permitting scale. Nature Communications 10: Article 1794.

Khandaker, M.R., A. Tauhidul, and C. Mahfuzulhoq. 2012. Location based early disaster warning and evacuation system on mobile phones using OpenStreetMap. IEEE Conference on Open Systems. http://users.cis.fiu.edu/ talam005/ICOS12.pdf. Accessed 12 Nov 2020
Kierkegaard, S. 1991. The notion of fear (Der Begriff Angst). Hamburg: Europäische Verlagsanstalt (in German).

Koerth, J., A.T. Vafeidis, J. Hinkel, and H. Sterr. 2013. What motivates coastal households to adapt pro-actively to sea-level rise and increasing flood risk?. Regional Environmental Change 13(4): 897-909.

Kron, W. 2002. Flood risk $=$ hazard $\times$ exposure $\times$ vulnerability. In Flood defence, ed. B. Wu, Z.-Y. Wang, G. Wang, G. Huang, H. Fang, and J. Huang, 82-97. New York: Science Press.

Kron, W. 2005. Flood risk = hazard values vulnerability. Water International 30(1): 58-68.

Lave, T.R., and L.B. Lave. 1991. Public perception of the risks of floods: Implications for communication. Risk Analysis 11(2): 255-267.

Lechowska, E. 2018. What determines flood risk perception? A review of factors of flood risk perception and relations between its basic elements. Natural Hazards 94(3): 1341-1366.

Lindell, M.K., C.S. Prater, C.E. Gregg, E.J. Apatu, S.-K. Huang, and H.C. Wu. 2015. Households' immediate responses to the 2009 American Samoa Earthquake and Tsunami. International Journal of Disaster Risk Reduction 12: 328-340.

Luhmann, N. 1993. Risk: A sociological theory. New York: Aldine de Gruyter.

Lumbroso, D. 2020. Flood risk management in Africa. Journal of Flood Risk Management 13(3): Article e12612.

Lumbroso, D., E. Brown, and N. Ranger. 2016. Stakeholders' perceptions of the overall effectiveness of early warning systems and risk assessments for weather-related hazards in Africa, the Caribbean and South Asia. Natural Hazards 84(3): 2121-2144.

Mertens, K., L. Jacobs, J. Maes, J. Poesen, M. Kervyn, and L. Vranken. 2018. Disaster risk reduction among households exposed to landslide hazard: A crucial role for self-efficacy?. Land Use Policy 75: 77-91.

Messner, F., and V. Meyer. 2005. Flood damage, vulnerability and risk perception - Challenges for flood damage research. UFZDiscussion Paper 13/2005. Leipzig, Germany: Helmholtz Center for Environmental Research (UFZ). http://hdl.handle.net/10419/ 45258. Accessed 20 Dec 2016.

Middelmann, M.H. 2007. Natural hazards in Australia. Identifying risk analysis requirements. Sidney: Bureau of Meteorology, Australian Government.

Molua, E.L. 2011. Farm income, gender differentials and climate risk in Cameroon: Typology of male and female adaptation options across agroecologies. Sustainability Science 6(1): 21-35.

Neisi, M., M. Bijani, E. Abbasi, H. Mahmoudi, and H. Azadi. 2020. Analyzing farmers' drought risk management behavior: Evidence from Iran. Journal of Hydrology 590: 125-243.

OECD (Organization for Economic Cooperation and Development). 2018. DAC list of ODA recipients. Paris: OECD. http://www. oecd.org/dac/financing-sustainable-development/developmentfinance-standards/daclist.htm. Accessed 5 Feb 2019.

Oltedal, S., B.-E. Moen, H. Klempe, and T. Rundmo. 2004. Explaining risk perception: An evaluation of cultural theory. Trondheim, Norway: Rotunde.

Oswald, M.E. 1994. Trust - An analysis from a psychological perspective (Vertrauen - eine Analyse aus psychologischer Sicht). In Law and conduct (Recht und Verhalten), ed. H. Hof, H. Kummer, and P. Weingart, 111-128. Baden-Baden, Germany: Nomos (in German).

Paton, D. 2008. Risk communication and natural hazard mitigation: How trust influences its effectiveness. International Journal of Global Environmental Issues 8(1-2): 2-16.

Peacock, W.G., S.D. Brody, and W. Highfield. 2005. Hurricane risk perceptions among Florida's single family homeowners. Landscape and Urban Planning 73(2): 120-135. 
Peters, E., and P. Slovic. 1996. The role and affect and worldviews as orienting dispositions in the perception and acceptance of nuclear power. Journal of Applied Social Psychology 26(16): $1427-1453$.

Plapp, T., and U. Werner. 2006. Understanding risk perception from natural hazards: Examples from Germany. In RISK 21 - Coping with risks due to natural hazards in the 21st century, ed. W. Ammann, S. Dannenmann, and L. Vulliet, 101-108. London: Taylor \& Francis.

Pohlmann, S. 2015. Gender and vulnerability: A gender-based study in Babessi in North West Cameroon (Gender und Vulnerabilität: Eine geschlechtsdifferenzierte Untersuchung im überflutungsgefährdeten Gebiet Babessi in Nordwest Kamerun). Master thesis. Neubiberg, Germany: Universität der Bundeswehr München (in German).

Qasim, S., A.N. Khan, R.P. Shrestha, and M. Qasim. 2015. Risk perception of the people in the flood prone Khyber Pukhthunkhwa Province of Pakistan. International Journal of Disaster Risk Reduction 14: 373-378.

Raaijmakers, R., J. Krywkow, and A. Van der Veen. 2008. Flood risk perceptions and spatial multi-criteria analysis: An exploratory research for hazard mitigation. Natural Hazards 46(3): 307-322.

Rogers, R.W. 1975. A protection motivation theory of fear appeals and attitude change. The Journal of Psychology: Interdisciplinary and Applied 91(1): 93-114.

Rogers, R.W. 1983. Cognitive and physiological processes in fearbased attitude change: A revised theory of protection motivation. In Social psycho-physiology: A sourcebook, ed. J. Cacioppo, and R. Petty, 153-176. New York: Guilford Press.

Rogers, R.W., and S. Prentice-Dunn. 1997. Protection motivation theory. In Handbook of health behavior research I: Personal and social determinants, ed. D.S. Gochman, 113-132. New York: Plenum Press.

Seo, S.N. 2010. Is an integrated farm more resilient against climate change? A micro-econometric analysis of portfolio diversification in African agriculture. Food Policy 35(1): 32-40.

Schelfaut, K., B. Pannemans, I. van der Craats, J. Krywkow, J. Mysiak, and J. Cools. 2011. Bringing flood resilience into practice: The FREEMAN project. Environmental Science \& Policy 14(7): 825-833.

Schendera, C.F.G. 2014. Regression analysis with SPSS (Regressionsanalysemit SPSS), vol 2. Oldenbourg, Germany: Wissenschaftsverlag (in German).

Schipper, E.L.F. 2010. Religion as an integral part of determining and reducing climate change and disaster risk: An agenda for research. In Climate change - Social science perspectives (Der Klimawandel - Sozialwissenschaftliche Perspektiven), ed. M. Voss, 377-393. Wiesbaden, Germany: VS Verlag für Sozialwissenschaften (in German).

Schrieder, G. 1996. The role of rural finance for food security of the poor in Cameroon. Frankfurt: Lang.

Short, J.F. 1984. The social fabric at risk: Toward the social transformation of risk analysis. American Sociological Review 49(6): 711-725.

Siegrist, M., and G. Cvetkovich. 2000. Perception of hazards: The role of social trust and knowledge. Risk Analysis 20(5): 713-720.

Siegrist, M., and H. Gutscher. 2008. Natural hazards and motivation for mitigation behavior: People cannot predict the affect evoked by a severe flood. Risk Analysis 28(3): 771-778.

Sivakumar, M.V.K. 2005. Impacts of natural disasters in agriculture, rangeland and forestry: An overview. In Natural disaster and extreme events in agriculture, ed. M.V.K. Sivakumar, R.P. Motha, and P. Haripada, 1-20. Berlin: Springer.

Sjöberg, L., B.-E. Moen, and T. Rundmo. 2004. Explaining risk perception An evaluation of the psychometric paradigm in risk perception research. Rotunde: Trondheim.
Slovic, P. 1987. Perception of risk. American Association for the Advancement of Science 236(4799): 280-285.

Slovic, P., ed. 2000. In Risk, society, and policy series: The perception of risk. London: Earthscan.

Slovic, P., B. Fischhoff, and S. Lichtenstein. 1985. Characterizing perceived risk. In Perilous progress: Managing the hazards of technology, Westview Special Studies in Science, Technology, and Public, ed. R.W. Kates, C. Hohenemser, and J.X. Kasperson, 91-125. Boulder, CO: Westview Press.

Smith, K. 2013. Environmental hazards: Assessing risk and reducing disaster. London: Routledge.

Sooryamoorthy, R., and R. Chetty. 2015. Studies on African families: In hindsight. Journal of Comparative Family Studies 46(1): 21-37.

Statista. 2020. Natural disasters. https://www.statista.com/study/ 10156/natural-disasters-statista-dossier/. Accessed 6 Nov 2020.

Stillwell, H.D. 1992. Natural hazards and disasters in Latin America. Natural Hazards 6(2): 131-159.

UN Desa (United Nations, Department of Economics and Social Affairs). 2015. 2014 revision report: World urbanization prospects. New York: UN DESA.

UNISDR (United Nations International Strategy for Disaster Reduction). 2009. International strategy for disaster reduction. UNISDR Terminology on disaster risk reduction. New York: UNISDR.

UNISDR (United Nations International Strategy for Disaster Reduction). 2015. Sendai framework for disaster risk reduction 2015-2030. New York: UNISDR. https://www.undrr.org/publi cation/sendai-framework-disaster-risk-reduction-2015-2030. Accessed 5 Nov 2020.

Vittinghoff, E., and C.E. McCulloch. 2007. Relaxing the rule of ten events per variable in logistic and Cox regression. American Journal of Epidemiology 165(6): 710-718.

Wagner, K. 2010. Climate change as a trigger for rapid change in "natural hazard management" (Der Klimawandel als Auslöser eines rapiden Wandels im "Naturgefahrenmanagement"). In Climate change - Social science perspectives (Der Klimawandel - Sozialwissenschaftliche Perspektiven), ed. M. Voss, 363-376. Wiesbaden, Germany: VS Verlag für Sozialwissenschaften (in German).

Wachinger, G., and O. Renn. 2010. Risk perception and natural hazards. CapHaz-Net WP3 report. Stuttgart, Germany: DIALOGIK Non-Profit Institute for Communication and Cooperative Research. http://caphaz-net.org/outcomes-results/CapHaz-Net_ WP3_Risk-Perception.pdf. Accessed 21 Feb 2019.

Wachinger, G., O. Renn, C. Begg, and C. Kuhlicke. 2013. The risk perception paradox - Implications for governance and communication of natural hazards. Risk Analysis 33(6): 1049-1065.

Wildavsky, W.A., and K. Dake. 1990. Theories of risk perception: Who fears what and why? Daedalus 119(4): 41-60.

Wilhite, D.A., ed. 2000. In Droughts: A global assessment. Abingdon, UK: Routledge.

World Bank. 2014. Managing disaster risk for resilient development. Washington, DC: World Bank. http://www.worldbank.org/en/ results/2013/04/12/managing-disaster-risks-resilient-develop ment. Accessed 6 Feb 2019.

Wotchoko, P., J.-M. Bardintzeff, Z. Itiga, D.G. Nkouathio, C.S. Guedjeo, G. Ngnoupeck, A. Dongmo, and P. Wandji. 2016. Geohazards (floods and landslides) in the Ndop Plain. Cameroon Volcanic Line. Open Geosciences 8(1): 429-449.

Wuepper, D., D. Zilberman, and J. Sauer. 2020. Non-cognitive skills and climate change adaptation: Empirical evidence from Ghana's pineapple farmers. Climate and Development 12(2): 151-162.

Yu, J., A.M. Cruz, and A. Hokugo. 2017. Households' risk perception and behavioral responses to Natech accidents. International Journal of Disaster Risk Science 8(1): 1-15. 